\title{
Bidder collusion at first-price auctions
}

\author{
Giuseppe Lopomo · Leslie M. Marx • Peng Sun
}

Received: 3 July 2009 / Accepted: 7 June 2010

(C) Springer-Verlag 2010

\begin{abstract}
We show that in simple environments, a bidding ring operating at a firstprice sealed-bid auction cannot achieve any gains relative to non-cooperative bidding if the ring is unable to control the bids that its members submit at the auction. This contrasts with results for the case in which the ring can control its members' bids or prevent all but one of the ring members from participating in the auction. Numerical examples suggest that this result extends to some more complex environments. The analytic results use linear programming techniques that have potential applications to a number of other economic problems.
\end{abstract}

Keywords Mechanism design $\cdot$ Cartel $\cdot$ Bidding ring $\cdot$ Linear programming

JEL Classification $\quad \mathrm{C} 61 \cdot \mathrm{C} 72 \cdot \mathrm{D} 44 \cdot \mathrm{K} 21 \cdot \mathrm{L} 41$

\section{Introduction}

The economics literature on mechanism design provides techniques for analyzing how individual preferences can be elicited to make collective decisions. ${ }^{1}$ These techniques

\footnotetext{
1 See the foundational paper Hurwicz (1973), surveys in Eatwell et al. (1989), Myerson (1989) and Ledyard (1989), and the textbook Mas-Colell et al. (1995).
}

The authors thank the National Science Foundation for support under grant SES-0849349. We thank seminar participants at INFORMS 2009, Andrew Born, Peter Franklin, Bob Marshall, John Min, and Jim Smith for helpful comments.

G. Lopomo · L. M. Marx $(\varangle) \cdot$ P. Sun

Fuqua School of Business, Duke University, Durham, NC 27708, USA

e-mail: marx@duke.edu 
have been particularly useful in the design of auctions. ${ }^{2}$ Much of the auction design literature, however, assumes noncooperative behavior by the bidders. Unfortunately, auctions are often susceptible to collusion among the bidders (Pesendorfer 2000). ${ }^{3}$ Such collusion can decrease the revenue obtained by the seller and distort the efficiency of the final allocation. As a result, competition authorities have focused on prosecuting bidder collusion. According to a 1990 General Accounting Office Report, from 1982 to 1988 , over half of the criminal restraint of trade cases filed by the U.S. Department of Justice's Antitrust Division involved auction markets. ${ }^{4}$ Understanding the mechanisms by which bidders support collusive agreements can be valuable for informing the choice of auction format, as well as detecting and prosecuting cartels. ${ }^{5}$

In this paper, we focus on first-price sealed-bid auctions. ${ }^{6}$ Much of the auctions literature characterizes first-price auctions as less susceptible to collusion than other auction formats such as second-price and ascending-bid auctions, ${ }^{7}$ but our paper is the first to establish that in some environments first-price auctions are immune to certain types of bidder collusion. Our results contribute to the theoretical basis for the existing recommendation that sellers concerned about collusion use a first-price rather than second-price or ascending-bid auction. ${ }^{8}$

In a first-price auction, bidders simultaneously submit bids and the highest bidder is awarded the object and pays the amount of its bid. A bidder cartel would maximize its collusive gains if it could entirely suppress within-cartel rivalry and send only the highest-valuing ring member to the auction to bid against the non-cartel bidders. This outcome is obtained in the model of McAfee and McMillan (1992), a seminal paper on collusion at first-price auctions.

In McAfee and McMillan (1992), cartel members first bid for the right to be the sole cartel member to attend the auction. The highest bidding cartel member is sent to the main auction, while other cartel members are prevented from bidding at the main auction. McAfee and McMillan focus on the case of symmetric bidders and an all-inclusive cartel, in which case the mechanism is efficient and extracts all surplus from the seller. In equilibrium, the lone cartel member to attend the auction is the one with the highest value for the object, and that cartel member wins the object at a price equal to the seller's reserve price. This suggests a first-price auction is vulnerable to collusion. $^{9}$

\footnotetext{
2 Milgrom (1985, 1989), Wilson (1987), McAfee and McMillan (1992) and McMillan (1994).

3 For a recent example, see "Wide Inquiry on Rigged Bids in Municipal Bonds,"New York Times, January 9, 2009.

4 "GAO Report: Changes in Antitrust Enforcement Policies and Activities," GAO/GGD-91-2, October 1990, available at http://archive.gao.gov/d22t8/142779.pdf.

5 In the U.S., bid rigging is a per se violation of the Sherman Act. In an attempt to alert the public to the problem of bidder collusion and other price fixing schemes, the U.S. Department of Justice publishes the primer "Price Fixing \& Bid Rigging - They Happen: What They Are and What to Look For" (available at http://www.usdoj.gov/atr/public/guidelines/pfbrprimer.pdf).

6 Our results also apply to sealed-bid procurements, in which the lowest bidder wins, as long as the only dimension of the bid is price.

7 See, e.g., Robinson (1985), Marshall and Meurer (2004) and Marshall and Marx (2007).

8 See "Practical conclusion 1"of Kovacic et al. (2006).

9 See Sect. 2 for examples of prosecuted cases of collusion at first-price auctions.
} 
The mechanism of McAfee and McMillan relies on the assumption that the cartel can send one designated cartel member to the auction and prevent all others from submitting bids. Such a collusive mechanism where the cartel can control the bids of its members is referred to as "bid submission mechanism" (BSM) in Marshall and Marx (2007). One interpretation of a BSM is that one cartel member submits the bids for all of the cartel members. ${ }^{10}$

Although it may be possible for a cartel to implement a BSM in some settings, it may not be possible in others. For example, in settings where a cartel member can use a "shill" to submit bids on its behalf, it may be difficult or impossible for the cartel to monitor the bids of its members. The use of shill bidders is clearly possible in some settings, as evidenced by legal action against bidders placing shill bids, ${ }^{11}$ and is a general concern at online auctions. ${ }^{12}$ In these cases, the cartel may be forced to use a "bid coordination mechanism" (BCM), through which the cartel makes recommendations to its members about how they should bid, but cannot enforce those recommendations.

We consider the susceptibility of first-price auctions to the use of BCMs by coalitions of bidders. In contrast to McAfee and McMillan (1992) result that an all-inclusive cartel using a BSM at a first-price auction does not bid above the auctioneer's reserve price and so achieves the maximum collusive gain, we show that at least in simple symmetric environments, a cartel using a BCM can achieve no collusive gain at all. A cartel using a BCM at a first-price auction does no better than noncooperative bidding. ${ }^{13}$

When a cartel must use a BCM, rather than a BSM, the problem belongs to the class of "mixed models" that involve both adverse selection and moral hazard. ${ }^{14}$ That is, in addition to providing incentives for truthful revelation of private information, any viable collusive scheme must also provide incentives for cartel members to follow its bid recommendations. Typically, mixed models have proven difficult to analyze. In particular, the general framework of a "Bayesian game with communication" provided in Myerson (1991, Chapter 6.3), tends to be neither computationally nor analytically tractable.

In this paper we are able to reformulate the cartel problem as a linear optimization model with a polynomial number of constraints in the number of bidder types and allowable bids. We prove analytically that collusion using a BCM is not profitable for the case of an all-inclusive cartel with two symmetric bidders. We establish the result using an argument based on linear programming duality. Formally, we use duality arguments to establish an upper bound on the total surplus to bidders from the optimal BCM and then show that this upper bound converges to the total noncooperative

\footnotetext{
10 In U.S. v. W.F. Brinkley \& Son Construction Company, Inc (1986), Brinkley turned in the bid form for at least one of the other cartel members, presumably allowing him to monitor the other's bid.

11 See, e.g., "3 Men Are Charged With Fraud In 1,100 Art Auctions on EBay," New York Times, March 9, 2001. See also Albert (2002), especially footnotes 95 and 96.

12 See, e.g., "The Bidding Game: A special report; In Online Auction World, Hoaxes Aren't Easy to See," New York Times, June 2, 2000. “F.B.I. Opens Investigation Of EBay Bids,” New York Times, June 7, 2000. "Jeweler to Pay \$400,000 in Online Auction Fraud Settlement," New York Times, June 9, 2007.

13 For cartels using BCMs, Marshall and Marx (2007) formalize the notion that collusion is less profitable at a first-price auction than a second-price or ascending-bid auction but do not show the extent to which it is less profitable.

14 See, e.g., Laffont and Martimort (2002), Chapter 7.
} 
surplus as the bid increment goes to zero. The sequence of dual feasible solutions required in the proof is obtained using insights gained through the examination of numerical solutions. ${ }^{15}$ This is a novel approach in the economic analysis of this type of problem. We hope the techniques illustrated in this paper can be extended to a large variety of mechanism design applications.

Although our analytic results apply to a restricted environment, numerical solutions suggest that first-price auctions are also robust to collusion using BCMs in more general environments involving larger type spaces and asymmetric bidders.

The paper proceeds as follows. In Sect. 2, we provide background on bidder collusion at first-price auctions. In Sect. 3, we describe the model and the mechanism design problem of the cartel. In Sect. 4, we present our analytical results. These results focus on the case of two symmetric bidders, each with two possible types. In Sect. 5, we discuss numerical results for environments with asymmetries and with more than two types. Finally, in Sect. 6, we provide concluding discussion.

\section{Related literature on bidder collusion}

Bidding cartels at first-price auctions have been prosecuted in: U.S. v. A-A-A Elec. Co., Inc (1986), U.S. v. W.F. Brinkley \& Son Construction Company, Inc (1986), U.S. v. Raymond J. Lyon (1982) (sheet metal); and U.S. v. Addyston Pipe \& Steel Co. et al. (1897). In each of these cases, colluding bidders met prior to the auction to discuss their bids and determine transfer payments among the cartel members. For example, in U.S. v. Addyston Pipe, colluding cast-iron pipe manufacturers met prior to the auction, determined how the colluding firms would bid at the auction, and agreed on transfer payments:

“... the executive committee determines the price at which the bid is to be put in by some company in the association, and the question to which company this bid shall go is settled by the highest bonus which any one of the companies ... will agree to pay or bid for the order. ...the company to whom the right to bid upon the work is assigned sends in its estimate or bid to the city or company desiring pipe, and the amount thus bid is 'protected' by bids from such of the other members of the association as are invited to bid, and by the bidding in all instances being slightly above the one put in by the company to whom the contract is to go. ...Settlements are made at stated times of the bonus account debited against each company, where these largely offset each other, so that small sums are in fact paid by any company in balancing accounts." (U.S. v. Addyston Pipe \& Steel Co. et al. (1897) at p.3).

In this paper, we focus on collusion at first-price auctions in an environment where the cartel can communicate prior to the auction and enforce transfer payments among cartel members. However, because our main results are negative in the sense that they

\footnotetext{
15 Given sufficient computing power, our model is amenable to numerical analysis in discrete environments. Using noncooperative bidding as a benchmark, we can calculate the gains to bidders and loss to the seller generated by the collusive ring, for any given minimum bid increment. These computations indicate that both bidder gains and seller loss from collusion diminish when the bid increment decreases to zero.
} 
show profitable collusion is not possible, eliminating the ability of the cartel to determine transfer payments does not affect these results. In addition, we focus on a cartel operating at a one-shot auction. With repeated interaction, a number of authors have shown that, for sufficiently large discount factors, a cartel can do better than noncooperative play. ${ }^{16}$ In light of this body of work, our results suggest that limiting repeated interaction among the bidders may generate significant benefits for seller.

We focus on cartels that operate prior to the auction. Thus, we assume the cartel cannot condition transfer payments on the outcome of the auction, i.e., a cartel cannot impose penalties on its members after the auction, if the outcome does not correspond to the cartel's desired actions. Of course, a seller facing a cartel that relied on the observation of the auction's outcome to enforce cartel behavior would have an incentive to suppress information about auction outcomes beyond notifying the winning bidder that it had won and collecting payment.

We consider a cartel that cannot control the bids of its members, i.e., it must use a BCM. Marshall and Marx (2007) show that a cartel using a BCM can achieve the first-best collusive outcome at a second-price or ascending-bid auction but not a first-price auction. ${ }^{17}$ At a second-price or ascending-bid auction, the high-valuing cartel member need not change its bid relative to noncooperative bidding in order to obtain a collusive gain. In contrast, at a first-price auction, unless the high-valuing cartel member reduces its bid below its noncooperative bid, there is no collusive gain. This lowering of the high-valuing cartel member's bid creates incentives for cheating by other cartel members.

Although Marshall and Marx (2007) formalize the notion that collusion is less profitable at a first-price auction than at a second-price or ascending-bid auction, they do not show how much less profitable a BCM is at a first-price auction, and they leave as an open question the existence of a BCM that does better than noncooperative play at a first-price auction.

In this paper, we show that for simple environments with symmetric bidders, collusion using a BCM is not possible at a first-price auction in the sense that no BCM increases cartel surplus relative to noncooperative play. Thus, at least in the simple environments to which our results apply, a first-price auction is robust to collusion when the cartel cannot control the bids of its members.

\section{Model}

\subsection{Setup}

We focus on a single-object first-price auction with two bidders. Each risk neutral bidder $i \in\{1,2\}$ independently draws a private value $v_{i}$ from a distribution $F_{i}$ with finite support $\mathcal{V}_{i}$. Let $\mathcal{V} \equiv \mathcal{V}_{1} \times \mathcal{V}_{2}$. Let $f_{i}\left(v_{i}\right)$ be the probability that bidder $i$ 's value

\footnotetext{
16 See Oren and Rothkopf (1975), Aoyagi (2003), Skrzypacz and Hopenhayn (2004), Blume and Heidhues (2006), and Jamison and Hörner (2008).

17 See also the mechanism of Graham and Marshall (1987) for environments in which the cartel can condition on the identity of the winner and the price paid.
} 
is $v_{i}$. Where convenient we assume discrete bids, but with a vanishingly small bid increment. Let $\mathcal{B}$ denote the set of feasible bids.

As is standard for a first-price auction, each bidder submits a bid, and the high bidder wins and pays the amount of its bid. In the case of a tie, we assume the object is randomly allocated to one of the bidders with the high bid. We assume the seller knows the distributions from which bidders draw their values, but not the values themselves. We assume the seller is non-strategic in the sense that its reserve price is equal to the lower bound of the support of the bidders' value distributions. Our results, appropriately adjusted, continue to hold if the auctioneer sets a higher fixed reserve price. $^{18}$

Let $u_{i}\left(b_{1}, b_{2}, v_{i}\right)$ be bidder $i$ 's surplus in a first-price auction, given bidder $i$ 's value $v_{i}$ and bid vector $\left(b_{1}, b_{2}\right)$. That is,

$$
u_{i}\left(b_{1}, b_{2}, v_{i}\right) \equiv \begin{cases}v_{i}-b_{i}, & \text { if } b_{i}>b_{-i} \\ 0, & \text { if } b_{i}<b_{-i} \\ \left(v_{i}-b_{i}\right) / 2, & \text { otherwise }\end{cases}
$$

Both bidders are eligible to participate in a cartel. Even in environments with more than two bidders, the assumption of an all-inclusive cartel is common in the literature, particularly because the study of non-all-inclusive cartels at first-price auctions is made difficult by the lack of analytic bid functions. ${ }^{19}$

The cartel mechanism operates as follows: Each cartel member makes a report to a "center," which is a standard Myerson (1983) incentiveless mechanism agent. Based on these reports, the center recommends a bid to be made by each cartel member and requires payments from the cartel members. Cartel members observe only their own bid recommendations and required payments. We require that the center's budget be balanced in expectation.

We focus on incentive compatible collusive mechanisms, which, in our environment, has two dimensions: truth-telling and obedience. First, it must be incentive compatible for each cartel member to report its value truthfully. Second, it must be incentive compatible for each cartel member to follow the bid recommendation of the center. In addition, we require ex-ante individual rationality, so that a bidder's expected payoff from participation in the cartel is at least as great as its expected payoffs from noncooperative play. We assume the cartel can compel its members to make their required payments, but that it cannot prevent cartel members from participating in the auction.

The assumption of ex-ante individual rationality can be viewed as an assumption that cartel members must commit to participation in the cartel prior to learning their values and that the failure of either bidder to join results in the complete dissolution

\footnotetext{
18 As we show, in our environment a cartel using a BCM can do no better than noncooperative bidding, so there is no incentive for the auctioneer to use anything other than its optimal noncooperative reserve price. When facing a cartel using a BSM, an auctioneer would generally have an incentive to increase its reserve price because the optimal reserve price when facing $k$ noncoopertive bidders drawing values from distribution $F$ is less than or equal to the optimal reserve price when facing one bidder drawing its value from distribution $F^{k}$.
}

19 See Marshall et al. (1994) and Gayle and Richard (2008) for related numerical techniques. 
of the cartel. Because our result is a negative one, showing that optimal collusion does no better than noncooperative bidding, the use of a more restrictive assumption such as interim individual rationality, where cartel members make their participation decisions after learning their values, would not affect our findings.

In the environment we consider, even with more than two bidders, an all-inclusive cartel using a BCM at a second-price or ascending-bid auction can extract all the surplus from the seller (Marshall and Marx 2007). The cartel's surplus is equal to the highest value among the bidders and the seller receives zero (or the reserve price in the case of a positive reserve price).

\subsection{Mechanism design problem}

By the revelation principle, we restrict attention (without loss of generality) to the class of all incentive compatible and individually rational direct revelation mechanisms. Any incentive compatible and individually rational direct revelation mechanism specifies for each pair of reports $\left(v_{1}, v_{2}\right) \in \mathcal{V}$, (i) a probability distribution over all feasible bid pairs $p\left(\cdot \mid v_{1}, v_{2}\right) \in \triangle_{\mathcal{B} \times \mathcal{B}}$, where $\triangle_{\mathcal{B} \times \mathcal{B}}$ represents the probability simplex with each pair of bids as the vertex; and (ii) monetary transfers $m_{1}\left(v_{1}, v_{2}\right)$ and $m_{2}\left(v_{1}, v_{2}\right)$. The vector $\left(p, m_{1}, m_{2}\right)$ defines the cartel mechanism. Incentive compatibility for truthtelling implies that ring members have no incentive to misreport their values to the center. The probability distribution $p$ specifies the center's (possibly stochastic) bid recommendations to the two bidders - each bidder observes only its own recommended bid and not that of its rival. Incentive compatibility for obedience implies no bidder has an incentive to deviate from the bid recommendation it receives from the center. The payments $m_{1}$ and $m_{2}$ are the transfer payments from the bidders to the center and may be positive or negative. These payments are constrained to sum to zero in expectation in the ex-ante budget balance condition below.

The center's problem of maximizing expected cartel surplus can be written as follows (the notation below parallels that of Myerson (1985)): maximize the total expected surplus to the two bidders,

$$
\max _{p, m_{1}, m_{2}} \sum_{i \in\{1,2\},\left(v_{1}, v_{2}\right) \in \mathcal{V}, b_{1}, b_{2} \in \mathcal{B}} p\left(b_{1}, b_{2} \mid v_{1}, v_{2}\right) u_{i}\left(b_{1}, b_{2}, v_{i}\right) f_{1}\left(v_{1}\right) f_{2}\left(v_{2}\right),
$$

subject to $p$ representing a probability distribution, $\forall\left(v_{1}, v_{2}\right) \in \mathcal{V}$,

$$
p\left(\cdot \mid v_{1}, v_{2}\right) \in \triangle_{\mathcal{B} \times \mathcal{B}},
$$

ex-ante budget balance,

$$
\sum_{i \in\{1,2\},\left(v_{1}, v_{2}\right) \in \mathcal{V}} m_{i}\left(v_{1}, v_{2}\right) f_{1}\left(v_{1}\right) f_{2}\left(v_{2}\right)=0
$$


and incentive compatibility, $\forall i \in\{1,2\}, \forall v_{i}, v_{i}^{\prime} \in \mathcal{V}_{i}, \forall \delta_{i}: \mathcal{B} \rightarrow \mathcal{B}$,

$$
U_{i}^{*}\left(p, \delta_{i}, v_{i}^{\prime} \mid v_{i}\right)-U_{i}\left(p \mid v_{i}\right) \leq 0,
$$

where $U_{i}\left(p \mid v_{i}\right)$ is bidder $i$ 's expected surplus under truthtelling and obedience,

$$
\begin{aligned}
U_{i}\left(p \mid v_{i}\right) \equiv & \sum_{v_{-i} \in \mathcal{V}_{-i}, b_{i}, b_{-i} \in \mathcal{B}} p\left(b_{1}, b_{2} \mid v_{1}, v_{2}\right) u_{i}\left(b_{1}, b_{2}, v_{i}\right) f_{-i}\left(v_{-i}\right) \\
& -\sum_{v_{-i} \in V_{-i}} m_{i}\left(v_{1}, v_{2}\right) f_{-i}\left(v_{-i}\right)
\end{aligned}
$$

and $U_{i}^{*}\left(p, \delta_{i}, v_{i}^{\prime} \mid v_{i}\right)$ is bidder $i$ 's expected surplus when bidder $i$ 's value is $v_{i}$, it reports $v_{i}^{\prime}$, and it bids according to a deviation function $\delta_{i}\left(b_{i}\right)$ that depends on the center's recommendation $b_{i}$,

$$
\begin{aligned}
U_{1}^{*}\left(p, \delta_{1}, v_{1}^{\prime} \mid v_{1}\right) \equiv & \sum_{v_{2} \in \mathcal{V}_{2}, b_{1}, b_{2} \in \mathcal{B}} p\left(b_{1}, b_{2} \mid v_{1}^{\prime}, v_{2}\right) u_{1}\left(\delta_{1}\left(b_{1}\right), b_{2}, v_{1}\right) f_{2}\left(v_{2}\right) \\
& -\sum_{v_{2} \in \mathcal{V}_{2}} m_{1}\left(v_{1}^{\prime}, v_{2}\right) f_{2}\left(v_{2}\right)
\end{aligned}
$$

and

$$
\begin{aligned}
U_{2}^{*}\left(p, \delta_{2}, v_{2}^{\prime} \mid v_{2}\right) \equiv & \sum_{v_{1} \in \mathcal{V}_{1}, b_{1}, b_{2} \in \mathcal{B}} p\left(b_{1}, b_{2} \mid v_{1}, v_{2}^{\prime}\right) u_{2}\left(b_{1}, \delta_{2}\left(b_{2}\right), v_{2}\right) f_{1}\left(v_{1}\right) \\
& -\sum_{v_{1} \in \mathcal{V}_{1}} m_{2}\left(v_{1}, v_{2}^{\prime}\right) f_{1}\left(v_{1}\right)
\end{aligned}
$$

While most of the components of the above constrained optimization problem are straightforward, the incentive compatibility constraint in (4) deserves additional commentary. The incentive compatibility constraint in (4) incorporates both a truthtelling and an obedience constraint. It requires that a bidder not benefit from a simple misreporting of its value, where the bidder then follows the recommendation of the center; in addition, it requires that a bidder not benefit from any combination of misreporting its value and then using any information contained in the recommended bid it receives to choose a possibly different bid from the recommendation.

Because bidders must receive their recommended bids from the center prior to submitting their bids at the auction, bidders can potentially make use of inferences from the recommendation regarding the bidding behavior of its rival to adjust their bids. For this reason, we allow the deviation function $\delta_{i}$ in (4) to be a function of the bid recommendation bidder $i$ receives from the center. Incentive compatibility requires that given any strategy for reporting, either truthful or not, there is no deviation function $\delta_{i}$ mapping the bidder $i$ 's recommended bid from the center to its actual bid that improves upon $\delta_{i}\left(b_{i}\right)=b_{i}$.

Although the above formulation accounts for possible inferences made by a bidder regarding its rival's recommended bid based on the recommendation it receives, the 
formulation does not explicitly allow a bidder to make inferences regarding its rival based on the transfer payment required by the center. One might think that a bidder's required payment could be informative as to the rival's report because $m_{1}$ and $m_{2}$ are functions of the vector of reports. However, because only bidder $i$ 's expected payment given its own report, $M_{i}\left(v_{i}\right) \equiv \sum_{v_{-i} \in \mathcal{V}_{-i}} m_{i}\left(v_{1}, v_{2}\right) f_{-i}\left(v_{-i}\right)$, enters the problem above, one can show that any level of total surplus for the cartel that can be achieved with payments $m_{i}\left(v_{1}, v_{2}\right)$ and allowing for possible inferences by the bidders about their rivals can also be achieved with payments $M_{i}\left(v_{i}\right)$ that, because they depend only on $v_{i}$, do not allow such inferences. In effect, allowing the inferences only introduces additional incentive compatibility constraints, so allowing such inferences is never optimal. More formally, this result follows from Myerson (1982, Proposition 2), which implies that our formulation ignoring possible inferences from the required transfer payments is without loss of generality. In what follows, we simplify by replacing the transfer function $m_{i}\left(v_{1}, v_{2}\right)$ with the expected payment function $M_{i}\left(v_{i}\right)$.

One difficulty with the program defined in (1)-(7) is that the set of all possible deviation functions $\delta_{i}$ considered in the incentive compatibility constraint (4) is large (exponential to the number of feasible bids). In order to formulate the problem as a tractable linear program, we introduce the following new optimization problem which involves the function $J_{i}\left(v_{i}, v_{i}^{\prime}, b_{i}\right)$, which gives bidder $i$ 's expected surplus if it has type $v_{i}$, reports $v_{i}^{\prime}$, receives recommendation $b_{i}$ from the center, and bids optimally; multiplied by $\operatorname{Pr}\left(b_{i} \mid v_{i}^{\prime}\right)$, which is the probability of receiving recommendation $b_{i}$ given $i$ 's report $v_{i}^{\prime}$. The rewritten incentive compatibility constraint holds for all values $v_{i}$ and reports $v_{i}^{\prime}$, rather than for all values, reports, and bid deviation functions as in (4). The possibility of deviations from recommended bids is incorporated in the function $J_{i}\left(v_{i}, v_{i}^{\prime}, b_{i}\right)$.

The rewritten incentive compatibility constraint (12) states that bidder $i$ 's expected payoff from reporting truthfully and following the recommendation of the center is greater than or equal to $J_{i}\left(v_{i}, v_{i}^{\prime}, b_{i}\right)$ minus its expected transfer payment from reporting $v_{i}^{\prime}$. The value of $J_{i}\left(v_{i}, v_{i}^{\prime}, b_{i}\right)$ is constrained to be at least as great as the expected payoff that bidder $i$ with value $v_{i}$ could get from submitting any bid, conditional on having reported $v_{i}^{\prime}$ and received bid recommendation $b_{i}$ from the center. Thus, we conserve on constraints by considering only deviations from obedience that are optimal given a bidder's value, submitted report, and observed recommendation.

The rewritten objective function, probability constraints, and ex-ante budget balance condition are analogous to those in (1)-(7). The difference comes in the incentive compatibility constraint as described above.

Lemma 1 The center's problem can be written as follows:

$$
\max _{\rho, M_{1}, M_{2}, J_{1}, J_{2}} \sum_{i=1}^{2} \sum_{\left(v_{1}, v_{2}\right) \in \mathcal{V}, b_{1}, b_{2} \in \mathcal{B}} \rho\left(b_{1}, b_{2}, v_{1}, v_{2}\right) u_{i}\left(b_{1}, b_{2}, v_{i}\right) f_{1}\left(v_{1}\right) f_{2}\left(v_{2}\right)
$$

subject to $\rho$ representing a conditional probability distribution, $\forall\left(v_{1}, v_{2}\right) \in \mathcal{V}$, $\forall\left(b_{1}, b_{2}\right) \in \mathcal{B} \times \mathcal{B}$ 


$$
\rho\left(b_{1}, b_{2}, v_{1}, v_{2}\right) \geq 0,
$$

and $\forall\left(v_{1}, v_{2}\right) \in \mathcal{V}$,

$$
\sum_{b_{1}, b_{2} \in \mathcal{B}} \rho\left(b_{1}, b_{2}, v_{1}, v_{2}\right)=1
$$

ex-ante budget balance,

$$
\sum_{\left(v_{1}, v_{2}\right) \in \mathcal{V}}\left(M_{1}\left(v_{1}\right) f_{1}\left(v_{1}\right)+M_{2}\left(v_{2}\right) f_{2}\left(v_{2}\right)\right)=0
$$

incentive compatibility, $\forall i \in\{1,2\}, \forall v_{i} \in \mathcal{V}_{i}, \forall v_{i}^{\prime} \in \mathcal{V}_{i}$,

$$
\begin{aligned}
& \sum_{v_{-i} \in \mathcal{V}_{-i}, b_{1}, b_{2} \in \mathcal{B}} \rho\left(b_{1}, b_{2}, v_{1}, v_{2}\right) u_{i}\left(b_{1}, b_{2}, v_{i}\right) f_{-i}\left(v_{-i}\right)-M_{i}\left(v_{i}\right) \\
& \geq \sum_{b_{i} \in \mathcal{B}} J_{i}\left(v_{i}, v_{i}^{\prime}, b_{i}\right)-M_{i}\left(v_{i}^{\prime}\right)
\end{aligned}
$$

and the definition of $J, \forall v_{1} \in \mathcal{V}_{1}, \forall v_{1}^{\prime} \in \mathcal{V}_{1}, \forall b_{1} \in \mathcal{B}, \forall b_{1}^{\prime} \in \mathcal{B}$,

$$
J_{1}\left(v_{1}, v_{1}^{\prime}, b_{1}\right) \geq \sum_{v_{2} \in \mathcal{V}_{2}, b_{2} \in \mathcal{B}} \rho\left(b_{1}, b_{2}, v_{1}^{\prime}, v_{2}\right) u_{1}\left(b_{1}^{\prime}, b_{2}, v_{1}\right) f_{2}\left(v_{2}\right),
$$

$\forall v_{2} \in \mathcal{V}_{2}, v_{2}^{\prime} \in \mathcal{V}_{2}, b_{2} \in \mathcal{B}, b_{2}^{\prime} \in \mathcal{B}$,

$$
J_{2}\left(v_{2}, v_{2}^{\prime}, b_{2}\right) \geq \sum_{v_{1} \in \mathcal{V}_{1}, b_{1} \in \mathcal{B}} \rho\left(b_{1}, b_{2}, v_{1}, v_{2}^{\prime}\right) u_{2}\left(b_{1}, b_{2}^{\prime}, v_{2}\right) f_{1}\left(v_{1}\right)
$$

Proof See "Appendix A".

Using Lemma 1, we can apply linear programming techniques to analyze the optimal collusive mechanism in the first-price auction. In Sect. 4 we focus on symmetric bidders, and in Sect. 5 we explore extensions numerically.

\section{Analytical results for two symmetric bidders and two types}

In this section, we show that profitable collusion is not possible at a first-price auction using a BCM for simple auction environments. Specifically, we consider an environment with two symmetric bidders and discrete bids, and show that as the bid increment approaches zero, bidder surplus from the optimal BCM approaches that from noncooperative bidding. Thus, although discrete bids may create an environment in which bidders can profitably collude at a first-price auction using a BCM, the benefit from such collusion vanishes as the bid increment approaches zero. 
Even without the use of transfer payments, a cartel could achieve any correlated equilibrium (in the sense of Forge (2006) communication equilibria for games with incomplete information). Thus, our result implies that in our environment the best correlated equilibrium from the perspective of the cartel is a Nash equilibrium. ${ }^{20}$

In this section we assume symmetry, which means that $\mathcal{V}_{1}=\mathcal{V}_{2}$ and that for any value $v \in \mathcal{V}_{i}$ and bids $b_{1}, b_{2} \in \mathcal{B}$, we have $f_{1}(v)=f_{2}(v)$ and $u_{1}\left(b, b^{\prime}, v\right)=$ $u_{2}\left(b^{\prime}, b, v\right)$. Therefore, in this section we suppress the subscripts on $f_{i}$ and $u_{i}$, letting $u\left(b, b^{\prime}, v\right)=u_{1}\left(b, b^{\prime}, v\right)$.

The proof of the main result of this section relies on the assumption that each bidder has two possible values, $h$ and $l, h>l>0$. As discussed in Sect. 6, our numerical investigations suggest our results may continue to hold in some more general settings.

\subsection{Noncooperative benchmark with two bidders and two types}

For the two-type case, the following proposition describes the surplus from a noncooperative equilibrium.

Proposition 1 Assume two bidders, each having value $l$ with probability $f(l)$ and value $h$ with probability $f(h)=1-f(l)$, where $0<l<h$. The noncooperative equilibrium of the first-price auction game is as follows: a bidder with value l bids $l$; a bidder with value $h$ bids according to the following cumulative distribution

$$
F(b)= \begin{cases}0, & \text { if } b<l \\ \frac{f(l)(b-l)}{f(h)(h-b)}, & \text { if } b \in\left[l, b^{*}\right] \\ 1, & \text { otherwise, }\end{cases}
$$

where $b^{*} \equiv \operatorname{lf}(l)+h f(h)$.

Proof See “Appendix C”.

Using Proposition 1, we can characterize the noncooperative equilibrium as follows.

Corollary 1 In the environment of Proposition 1, the noncooperative equilibrium outcome is efficient, expected bidder surplus is $2(h-l) f(h) f(l)$, and expected seller revenue is $f(l)(1+f(h)) l+f(h)^{2} h$.

With this noncooperative outcome as a benchmark, we can consider collusive outcomes.

\subsection{Collusion with two bidders and two types}

To take advantage of the assumption of symmetry, it is helpful to simplify the linear program for the optimal collusive mechanism given in (8)-(14). In particular, as shown in Lemma 2, we can work with the following formulation, where we use the

20 See Nau et al. (2003) on the relation between correlated and Nash equilibria. 
notation $v$ and $\bar{v}$ to denote the two bidders' values and $b$ and $\bar{b}$ their bids, and we use $\widehat{v}$ to denote a bidder's report (possibly different from its value) and $\widehat{b}$ a bidder's bid (possibly different from its recommendation from the center):

$$
\max _{\rho, M, J} \sum_{v, \bar{v} \in\{l, h\}} \sum_{b, \bar{b} \in \mathcal{B}}(u(b, \bar{b}, v)+u(\bar{b}, b, \bar{v})) \rho(b, \bar{b}, v, \bar{v}) f(v) f(\bar{v})
$$

subject to $\rho$ representing a conditional probability distribution, $\forall v, \bar{v} \in\{l, h\}$, $\forall(b, \bar{b}) \in \mathcal{B} \times \mathcal{B}$,

$$
\rho(b, \bar{b}, v, \bar{v}) \geq 0
$$

and $\forall v, \bar{v} \in\{l, h\}$,

$$
\sum_{b, \bar{b} \in \mathcal{B}} \rho(b, \bar{b}, v, \bar{v})=1
$$

ex-ante budget balance,

$$
\sum_{v \in\{l, h\}} M(v) f(v)=0
$$

incentive compatibility, $\forall v, \widehat{v} \in\{l, h\}$,

$$
\begin{aligned}
& \sum_{\bar{v} \in\{l, h\}} \sum_{b, \bar{b} \in \mathcal{B}}(\rho(b, \bar{b}, v, \bar{v})+\rho(\bar{b}, b, \bar{v}, v)) u(b, \bar{b}, v) f(\bar{v})-M(v) \\
& \geq \sum_{b \in \mathcal{B}} J(v, \widehat{v}, b)-M(\widehat{v})
\end{aligned}
$$

and the definition of $J, \forall v, \widehat{v} \in\{l, h\}, \forall b, \widehat{b} \in \mathcal{B}$,

$$
J(v, \widehat{v}, b) \geq \sum_{\bar{v} \in\{l, h\}} \sum_{\bar{b} \in \mathcal{B}}(\rho(b, \bar{b}, \widehat{v}, \bar{v})+\rho(\bar{b}, b, \bar{v}, \widehat{v})) f(\bar{v}) u(\widehat{b}, \bar{b}, v) .
$$

Lemma 2 below states that it is sufficient for us to work with the linear program (15)-(20). Given any feasible solution $\left(\rho, M_{1}, M_{2}, J_{1}, J_{2}\right)$ to the linear program (8)(14), we can construct a feasible solution $(\tilde{\rho}, J, M)$ to the linear program (15)-(20) with the same objective function value by combining potentially asymmetric components as follows: $\tilde{\rho}(b, \bar{b}, v, \bar{v})=\frac{1}{2}(\rho(b, \bar{b}, v, \bar{v})+\rho(\bar{b}, b, \bar{v}, v)), M=M_{1}+M_{2}$, and $J=J_{1}+J_{2}$. Similarly, from any feasible solution $(\tilde{\rho}, M, J)$ to $(15)-(20)$, we can construct a (symmetric) feasible solution $\left(\rho, J_{1}, J_{2}, M_{1}, M_{2}\right)$ to (8)-(14) with the same objective function value by decomposing the components as follows: $\rho(b, \bar{b}, v, \bar{v})=$ $\rho(\bar{b}, b, \bar{v}, v)=\frac{1}{2}(\tilde{\rho}(b, \bar{b}, v, \bar{v})+\tilde{\rho}(\bar{b}, b, \bar{v}, v)), M_{1}=M_{2}=\frac{M}{2}$, and $J_{1}=J_{2}=\frac{J}{2}$.

Lemma 2 The value of the objective function at the optimum is the same in (15)-(20) and in (8)-(14). 
In what follows, we define the bid increment to be $\Delta \equiv \frac{b^{*}-l}{2 B}$ for a given positive integer $B$. The set of feasible bids can be expressed as

$$
\mathcal{B}_{B} \equiv\left\{b_{j} \mid b_{j}=l+\Delta j \text { for } j \in\{0,1, \ldots, n B\}\right\}
$$

in which $n$ is a sufficiently large integer. Therefore, $b_{0}=l$ and $b_{2 B}=b^{*}$, and the interval $\left[l, b^{*}\right]$ contains $2 B+1$ feasible bids. We also allow bids arbitrarily higher than $b^{*}$ by having $n>2$. As the integer $B$ approaches infinity, the bidding increment $\Delta$ approaches zero. When it is clear in the context, we omit the subscript $B$ from $\mathcal{B}_{B}$.

We consider the lowest feasible bid to be $l$, which can be enforced by the seller setting a reservation price $l$. Such an assumption is without loss of generality as the bid increment shrinks to zero, as demonstrated by the following lemma, which states that for any given arbitrarily small bid increment $\Delta$, it is not incentive compatible for the collusive mechanism to recommend any bid below $l-2 \Delta$.

Lemma 3 A lower bound on the recommended bids in an incentive compatible BCM is $l-2 \Delta$.

\section{Proof See "Appendix C".}

The proof of Lemma 3 demonstrates that if the center recommends any bid lower than $l-2 \Delta$, a player can earn a higher surplus by deviating from it with a higher bid, assuming the other player follows the center's recommendation. Therefore, the recommendation of a lower bid is not incentive compatible.

Clearly, for any discrete bidding set $\mathcal{B}_{B}$, the noncooperative equilibrium is a feasible collusive mechanism, and therefore a feasible solution to the linear program (15)-(20). Therefore, one may attempt to numerically solve the linear optimization model and try to characterize the optimal solution. If this can be done, then it would be easy to observe what happens as $B$ approaches infinity. However, the linear program (15)(20) is highly degenerate and has multiple solutions for a given finite $B$. Therefore, even if we were able to solve the problem numerically, it would be extremely hard to characterize structures for its optimal solution.

In fact, it is not necessary to fully characterize the optimal solution. Consider the dual formulation of the linear program (15)-(20) when the bidding set is $\mathcal{B}_{B}$. Following weak duality, the dual objective value from any dual feasible solution is an upper bound to any primal feasible objective value, in particular the surplus from the noncooperative equilibrium. In order to prove our result, we construct a sequence of dual feasible solutions with surplus $D(B)$. We also construct a sequence of lower bounds, $N C(B)$, for the noncooperative equilibrium surplus. Then we show that both $D(B)$ and $N C(B)$ converge to the surplus from the continuous bid noncooperative equilibrium given in Corollary 1.

To this end, we first present the dual formulation of the linear program (15)-(20): ${ }^{21}$

$$
\min _{\lambda, \mu, \xi, \delta} \sum_{v, \bar{v} \in\{l, h\}} \lambda(v, \bar{v}) f(v) f(\bar{v})
$$

\footnotetext{
21 Given the complexity of the primal, it is difficult to provide an intuitive interpretation of the dual.
} 
subject to $\forall v, v^{\prime} \in\{l, h\}, \forall j \in\{0,1, \ldots, n B\}$,

$$
f\left(v^{\prime}\right) \sum_{j^{\prime}=0}^{2 B} \xi\left(v^{\prime}, v, j, j^{\prime}\right)=f(v) \mu\left(v, v^{\prime}\right),
$$

$\forall v, \bar{v} \in\{l, h\}, \forall j, \bar{j} \in\{0,1, \ldots, n B\}$

$$
\begin{aligned}
& \lambda(v, \bar{v})-\sum_{v^{\prime} \in\{l, h\}} \mu\left(v, v^{\prime}\right) u\left(b_{j}, b_{\bar{j}}, v\right)-\sum_{v^{\prime} \in\{l, h\}} \mu\left(\bar{v}, v^{\prime}\right) u\left(b_{\bar{j}}, b_{j}, \bar{v}\right) \\
& \quad+\sum_{v^{\prime} \in\{l, h\}} \sum_{j^{\prime}=0}^{2 B} \xi\left(v, v^{\prime}, j, j^{\prime}\right) u\left(b_{j^{\prime}}, b_{\bar{j}}, v^{\prime}\right) \\
& \quad+\sum_{v^{\prime} \in\{l, h\}} \sum_{j^{\prime}=0}^{2 B} \xi\left(\bar{v}, v^{\prime}, \bar{j}, j^{\prime}\right) u\left(b_{j^{\prime}}, b_{j}, v^{\prime}\right) \\
& \geq u\left(b_{j}, b_{\bar{j}}, v\right)+u\left(b_{\bar{j}}, b_{j}, \bar{v}\right),
\end{aligned}
$$

$\forall v \in\{l, h\}$

$$
\delta f(v)=f(v) \sum_{v^{\prime} \in\{l, h\}} \mu\left(v, v^{\prime}\right)-\sum_{v^{\prime} \in\{l, h\}} f\left(v^{\prime}\right) \mu\left(v^{\prime}, v\right),
$$

and $\forall v, v^{\prime} \in\{l, h\}, \forall j, j^{\prime} \in\{0,1, \ldots, n B\}$,

$$
\xi\left(v, v^{\prime}, j, j^{\prime}\right) \geq 0 \text { and } \mu\left(v, v^{\prime}\right) \geq 0 .
$$

The following lemma gives properties of a feasible solution to (21)-(25).

Lemma 4 There exists $(\bar{\xi}, \bar{\mu}, \bar{\lambda}, \bar{\delta})$ that is feasible in the linear program (21)-(25) and that generates dual objective value $D(B)=(h-l) f(h) f(l)\left(2+\frac{f(h)^{2}(1+f(l))}{2 B f(l)^{2}}\right)$, where $\lim _{B \rightarrow \infty} D(B)=2(h-l) f(h) f(l)$.

Proof See "Appendix B" for the expressions for $(\bar{\xi}, \bar{\mu}, \bar{\lambda}, \bar{\delta})$ and the proof.

As can be seen in "Appendix B", the proof of Lemma 4 is quite technical. We were able to construct the sequence of dual feasible solutions following insights obtained from observing and refining the dual optimal solutions numerically. Doing so would have been much more difficult in the absence of such numerical calculations to provide guidance.

The expressions for the dual feasible solution $(\bar{\xi}, \bar{\mu}, \bar{\lambda}, \bar{\delta})$, especially $\bar{\xi}\left(h, h, j, j^{\prime}\right)$ and $\bar{\xi}\left(h, h, j, j^{\prime}\right)$, appear to be quite involved. In order to provide some intuition, we illustrate the values of $\bar{\xi}\left(h, h, j, j^{\prime}\right)$ in Fig. 1 with $B=20$. A similar graph produced for $\bar{\xi}\left(l, h, j, j^{\prime}\right)$, not shown, is indistinguishable from Fig. 1.

In Fig. 1 , it can be seen that $\bar{\xi}\left(h, h, j, j^{\prime}\right)$ takes value 0 when $j>j^{\prime}$. When $j<j^{\prime}$, the values of $\bar{\xi}\left(h, h, j, j^{\prime}\right)$ tend to oscillate between 0 and $2 f(h) / f(l)$ along the $j^{\prime}$ 


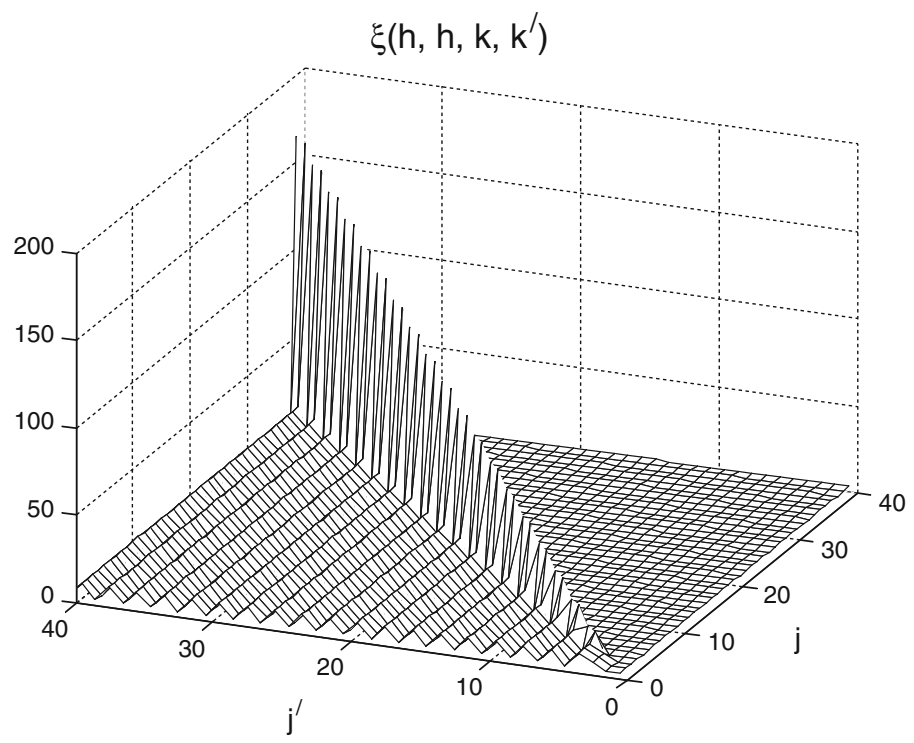

Fig. 1 Values of $\bar{\xi}\left(h, h, j, j^{\prime}\right)$ as a function of $j$ and $j^{\prime}$

dimension but remain constant at either 0 or $2 f(h) / f(l)$ along the $j$ dimension. Most prominently, most of the mass of $\bar{\xi}\left(h, h, j, j^{\prime}\right)$ concentrates along the diagonal $j=j^{\prime}$. Since for each $j$, the summation of $\bar{\xi}\left(h, h, j, j^{\prime}\right)$ along $j^{\prime}$ must be a constant, it is clear that such a construction of $\bar{\xi}\left(h, h, j, j^{\prime}\right)$ does not converge as $B$ approaches infinity. It remains an open question whether one can prove our result by working directly with the infinite dimensional linear program representing the continuous bid case.

As shown in Lemma 4, in the limit as the bid increment shrinks to zero (or the number of bids in the relevant interval increases to infinity), the dual objective value associated with our feasible solution converges to $2(h-l) f(h) f(l)$. For example, with a uniform distribution with $f(h)=f(l)=\frac{1}{2}$, this would be $(h-l) / 2$.

In order to characterize the collusive gain in the environment with discrete bid increments, it is important to characterize the corresponding noncooperative equilibrium. Although it is difficult to provide a general formula for the noncooperative equilibrium for any bid increment, we are able to provide a lower bound for the noncooperative equilibrium surplus in the following lemma.

Lemma 5 Given integer $B$ and the corresponding discrete feasible bidding set $\mathcal{B}_{B}$, there exists a symmetric noncooperative equilibrium such that the total surplus is at least $N C(B)=2 f(h) f(l)(h-l-\Delta)$.

Proof See "Appendix C".

The idea behind Lemma 5 is as follows. When a type $h$ bidder uses a mixed bidding strategy, any bid in the mix must generate the same surplus. We can calculate the surplus for a type $h$ bidder corresponding to the lowest bid in the mix above $l$, i.e., $l+\Delta$. If this bid is not in the mix, it means the bidder surplus can only be higher. Therefore, the 
surplus we have calculated provides a lower bound for the noncooperative equilibrium surplus.

Lemmas 4 and 5 imply our main result.

Proposition 2 Assuming two symmetric bidders and two possible values, in the limit as the bid increment converges to zero, the bidder surplus from the optimal BCM converges to the bidder surplus under noncooperative bidding.

Proof The result follows from the fact that $D(B)$ and $N C(B)$ are upper and lower bounds, respectively, of the optimal collusive bidder surplus for all $B$, and from Lemmas 4 and 5 which imply $\lim _{B \rightarrow \infty} N C(B)=\lim _{B \rightarrow \infty} D(B)$.

Proposition 2 implies that when bidders are symmetric, at least for environments with two bidders and two possible values, if the bid increment is sufficiently small, profitable collusion is not possible - a cartel can do no better than to bid noncooperatively. This suggests that when bidders are symmetric, a first-price auction is robust to collusion using a BCM.

\subsection{An example}

In this section we provide an example with two symmetric bidders and solve for the optimal BCM using linear programming. We compare the expected bidder surplus and expected seller revenue in the optimal BCM with that of the noncooperative equilibrium, which is characterized in Proposition 1. By varying the bid increments we also numerically demonstrate the speed of convergence.

Assume two symmetric bidders, each with value 40 or 80 with equal probability. Thus, in the notation above, $l=40, h=80, f(l)=f(h)=1 / 2$. With continuous bids, in the noncooperative equilibrium a bidder with value $l$ bids $l$ and a bidder with value $h$ bids according to the distribution

$$
F(b)= \begin{cases}0, & \text { if } b<l \\ \frac{b-l}{h-b}, & \text { if } b \in\left[l, \frac{h+l}{2}\right] \\ 1, & \text { otherwise. }\end{cases}
$$

Following Corollary 1, the noncooperative expected bidder surplus with continuous bids is 20 .

Figure 2 shows the lower bound of the noncooperative equilibrium surplus, as well as the surplus from the optimal BCM, based on the linear program (15)-(20) and its upper bound following Lemma 4. The figure shows that the optimal collusive surplus, as well as its upper and lower bounds, approach the noncooperative surplus as the bid increment approaches zero.

In this example, if the auction used a second-price or ascending-bid format instead of a first-price auction, the expected bidder surplus under noncooperative bidding would be 20 just as in the case of a first-price auction, but the optimal collusive surplus under a BCM would be 70, which is the expected value of the highest of the two bidders' values. Under noncooperative bidding, the seller's expected revenue is 50 . 


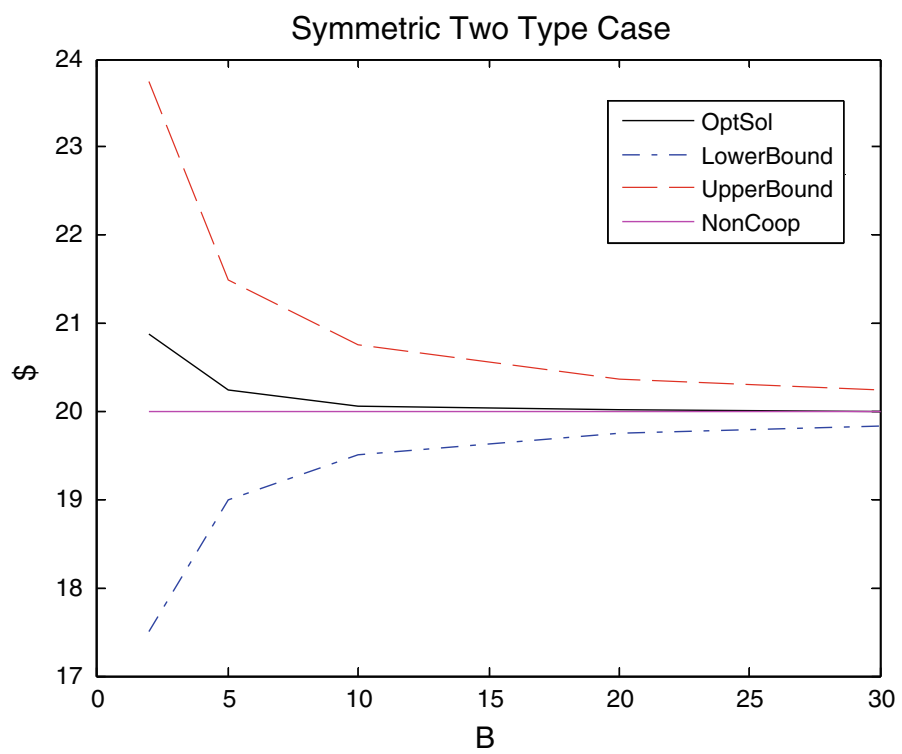

Fig. 2 The optimal collusive bidder surplus ("OptSol"), the upper bound $D(B)$ ("UpperBound"), the lower bound $N C(B)$ ("LowerBound"), and the noncooperative equilibrium surplus in the continuous bid case ("NonCoop") as a function of $B$, which is inversely related to the bid increment

Table 1 Comparison of auction formats

\begin{tabular}{lllllr}
\hline & \multicolumn{2}{l}{ Noncooperative bidding } & & \multicolumn{2}{l}{ Collusive bidding } \\
\cline { 2 - 3 } \cline { 5 - 6 } & First-price & Second-price & & First-price & Second-price \\
\hline Expected bidder surplus & 20 & 20 & & 20 & 70 \\
Expected seller revenue & 50 & 50 & & 50 & 0 \\
Expected total surplus & 70 & 70 & 70 & 70 \\
\hline
\end{tabular}

When the bidders do not collude, the seller is indifferent between the various auction formats, but when the bidders collude using a BCM, the seller's expected revenue is 50 with a first-price auction versus zero with a second-price or ascending-bid auction. This contrast is illustrated in Table 1.

We can illustrate our main result in terms of Fig. 3 below. Assuming no reserve price, total expected surplus of the seller and two bidders is equal to the expectation of the highest value between the bidders for either a second-price or first-price auction. Under noncooperative bidding, that surplus is divided between the seller and winning bidder. Under the optimal BCM or BSM at a second-price auction and under the optimal BSM at a first-price auction, the bidders capture all of the surplus. However, under the optimal BCM at a first-price auction, bidders can do no better than noncooperative bidding.

Under the optimal reserve price for a seller facing noncooperative bidders, the surplus in all cases would be inside the efficient frontier, and even further inside for the 


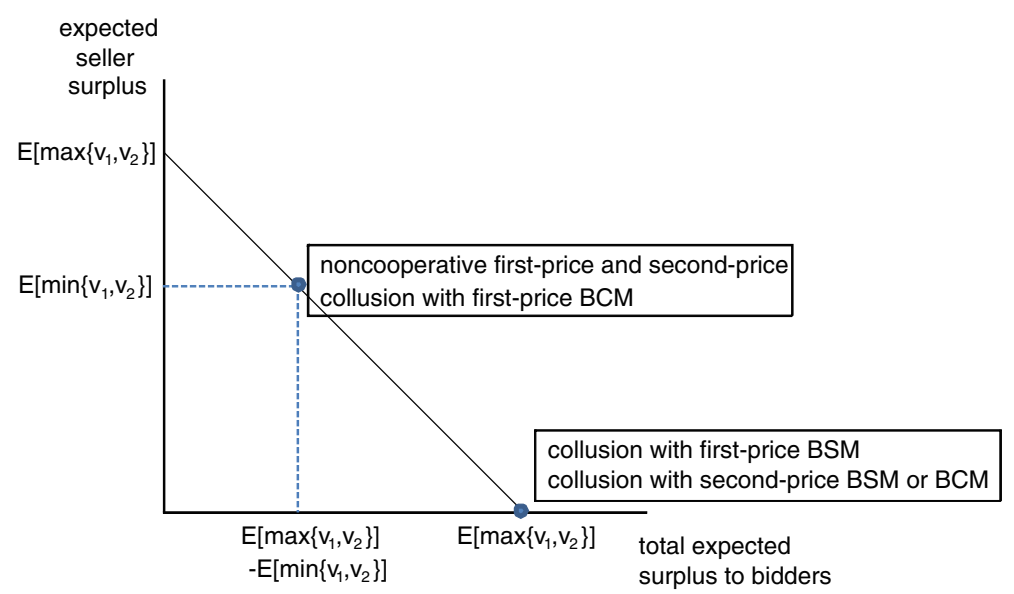

Fig. 3 Comparison of noncooperative and collusive outcomes

case of the optimal reserve price for a seller facing colluding bidders. But even with reserve prices of either type, it is still the case that the optimal BCM and BSM at a second-price auction and the optimal BSM at a first-price auction reduces the seller's surplus to zero. In contrast, the optimal BCM at a first-price auction can do no better than the noncooperative equilibrium, which shares surplus with the seller.

\section{Extension to more general settings}

To test the robustness of our results, in this section we numerically explore settings more general than assumed in our proof. In the first example, we consider asymmetric bidders, each with two potential types. In the second example, we consider symmetric bidders but more than two types.

\subsection{Asymmetric bidders}

We demonstrate, using simple examples, that the results of Sect. 4 continue to hold in some asymmetric environments, although the assumption of symmetry simplifies the proof. For asymmetric environments, we numerically solve linear programs with twotype bidders to verify that as bidding increment approaches 0 , the collusive surplus converges to the noncooperative equilibrium surplus.

Specifically, we focus on asymmetric environments with two bidders, where bidder $i$ has value $l_{i}$ with probability $p_{i}$ and value $h_{i}$ with probability $1-p_{i}$. We assume $l_{1}<h_{1}$ and $l_{2}<h_{2}$. Without loss of generality, assume $l_{1} \leq l_{2}$.

In any noncooperative equilibrium, the maximum bid submitted by each bidder must be the same, otherwise the bidder with the higher maximum bid could profitably deviate by lowering that bid slightly. For our current asymmetric environment, this 
maximum bid can be shown to be

$$
b^{m} \equiv\left(1-p_{1}\right) h_{2}+p_{1} l_{1},
$$

as long as that value is greater than $l_{2}$, so that bidder 2 with value $l_{2}$ does not want to bid more than $b^{m}$, and less than $h_{1}$, so that bidder 1 with value $h_{1}$ is willing to bid up to $b^{m}$. It is clear from the definition of $b^{m}$ that $h_{2}$ is greater than $b^{m}$, so bidder 2 with value $h_{2}$ is willing to bid up to $b^{m}$. Thus, the result below applies to the case with $l_{2}<b^{m}<h_{1}$. (Note that $b^{*}$ defined in Proposition 1 is analogous and plays a similar role.)

As in the case of our symmetric example, our benchmark is the noncooperative equilibrium with continuous bids. The equilibrium has bidder 1 with value $l_{1}$ mix aggressively below $l_{1}$, bidder 2 with value $l_{2}$ bid $l_{1}$, bidder 1 with value $h_{1}$ mix on $\left(l_{1}, b^{m}\right]$, and bidder 2 with value $h_{2}$ mix on $\left[l_{1}, b^{m}\right]$ with an atom on $l_{1}$. For a formal statement of the equilibrium, see the proof of Proposition 3.

Proposition 3 Assume two bidders, where bidder $i$ has value $l_{i}$ with probability $p_{i}$ and value $h_{i}$ with probability $1-p_{i}$, where $0<l_{i}<h_{i}$. Without loss of generality, let $l_{1} \leq l_{2}$. Assume $l_{2}<b^{m}<h_{1}$. In the noncooperative equilibrium of the first-price auction game, expected total bidder surplus is

$$
\left(h_{1}-b^{m}\right)\left(1-p_{1}\right)+\left(h_{2}-b^{m}\right)\left(1-p_{2}\right)+\left(l_{2}-l_{1}\right) p_{1} p_{2} .
$$

\section{Proof See “Appendix C”.}

We tested a number of cases with various choices of $l_{1}, l_{2}, h_{1}, h_{2}, p_{1}$ and $p_{2}$ satisfying the conditions of Proposition 3. When the bid increment becomes small, we always observe the optimal collusive surplus being close to the benchmark (26). We illustrate the typical findings in the computation using the following example.

Consider the following types and probabilities: $l_{1}=l_{2}=4, h_{1}=100, h_{2}=50$, and $p_{1}=p_{2}=0.5$. In this case the noncooperative equilibrium involves the low type bidding 4 and the high types randomizing on $\left(l_{1}, b^{m}\right]=(4,27]$, with an atom for bidder 2 with type $h_{2}=50$ on a bid of 4 . The expected bidder surplus is 48 .

Similar to before, we define the bid increment $\Delta$ to be $\left(b^{m}-l_{1}\right) /(2 B)$ for some integer $B$. In Fig. 4 , we plot the surplus from the optimal BCM as a function of $B$. It depicts the behavior typical of all the cases we tested, showing that the optimal collusive surplus approaches the noncooperative surplus as $B$ increases. Interestingly, in this particular figure, the approaching takes place from below. This is because in this example, the noncooperative bidder surplus for the discrete-bid case also approaches the continuous-bid surplus from below.

Note that the profitability of a BCM at a second-price or ascending-bid auction is not affected by asymmetries among the bidders. Thus, as in the symmetric example above, a cartel using a BCM can extract all of the surplus from the seller if the auction format is second-price or ascending-bid. So once again, when bidders collude 


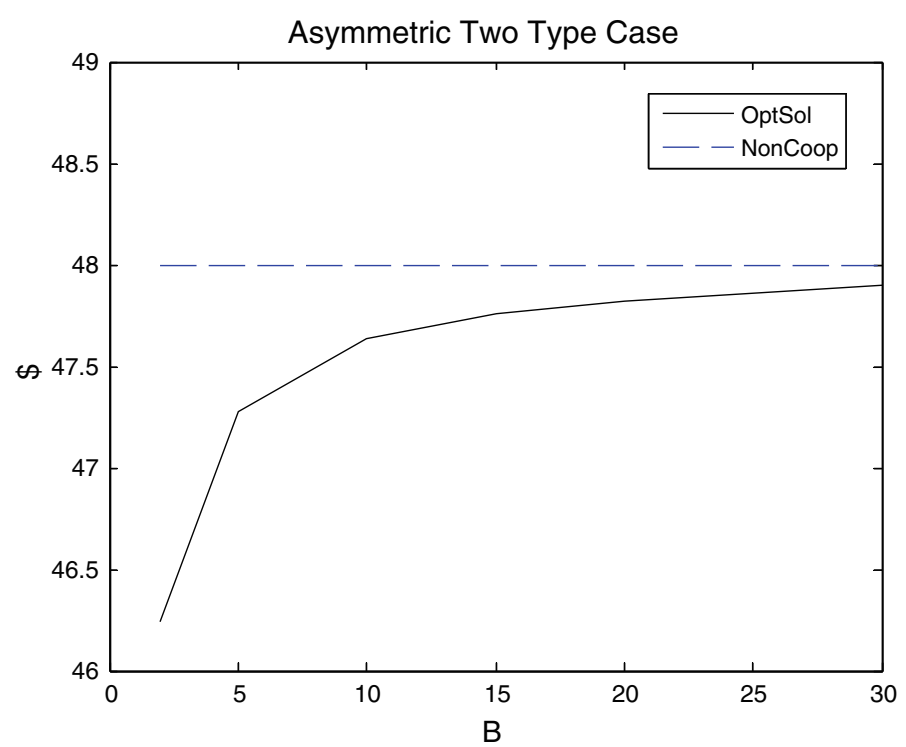

Fig. 4 Asymmetric bidder surplus ("OptSol") as a function of $B$. The dashed line at 48 ("NonCoop") is the noncooperative surplus for the continuous bid case

using a BCM, we have a stark contrast between the seller's expected revenue at a first-price auction, which is equal to its noncooperative value, and the seller's revenue at a second-price or ascending-bid auction, which is zero.

\subsection{More than 2 types}

In the following example, we consider $n>2$ types. We construct a feasible bid set with $n$ bids such that each type of bidder bids a corresponding bid in the set. We then numerically confirm that the optimal BCM coincides the noncooperative equilibrium. This example suggests that the result that is proved in the previous section may hold more generally in other symmetric bidder settings.

Consider two symmetric bidders each with a discrete uniform bid type distribution with support $\{1,2, \ldots, n\}$. Consider the bid set $\left\{b_{1}, b_{2}, \ldots, b_{n}\right\}$, where $b_{j}=\frac{j(j-1)}{2 j-1}$. In this environment, one can show the following result.

Proposition 4 There exists a noncooperative equilibrium in which a type $j$ bidder bids $b_{j}$.

The proof involves tedious but straightforward verifying the conditions for the equilibrium, and therefore is omitted in the paper.

Numerical calculations of the linear program with $n=2,3, \ldots, 14$ show that, in each case, the noncooperative equilibrium bidding strategy coincides with the bids in the optimal BCM. This suggests that as the type support approaches the continuum, profitable collusion at a first-price auction using a BCM is not possible. We leave the formal proof of such a result to later research. 


\section{Conclusion}

In this paper, we consider first-price collusive mechanisms that cannot directly control the cartel members' bids at the auction, but rather can only coordinate cartel members' bids through non-binding recommendations. These mechanisms are referred to as bid coordination mechanisms (BCMs). Thus, the collusive mechanisms we consider differ from those of McAfee and McMillan (1992), who assume bid submission mechanisms (BSMs) in which the cartel can prevent all but one designated cartel member from bidding at the auction. Focusing on BCMs, we show that for an environment with two symmetric bidders each with two possible values and sufficiently small bid increments, bidders cannot profitably collude. Any BCM that recommends bids that are less than the noncooperative bids is subject to cheating by ring members. Numerical calculations suggest that the result extends to more general symmetric environments and at least some asymmetric environments. This is in stark contrast to the results for second-price and ascending-bid auctions, where Marshall and Marx (2007) show that a cartel using a BCM can achieve the first-best collusive outcome, extracting all the surplus from the seller. Thus, this research supports the recommendation that sellers concerned about bidder collusion should use a first-price auction format.

We take a linear programming approach to the problem. We are able to construct the dual feasible solution (given in Lemma 4) by observing linear programming computations. In our case, numerical computations were invaluable for proving our analytical results. These same linear programming techniques are potentially useful in developing answers to a number of open questions.

We conclude by offering some examples of applications where we think this type of approach might be fruitful. Lopomo et al. (2005) show that the optimal collusive mechanism for an ascending-bid auction with post-auction knockout is inefficient, ${ }^{22}$ but they do not characterize or construct an optimal mechanism, so the nature and extent of the inefficiency is unclear. The collusive mechanisms for second-price auctions studied by Graham and Marshall (1987) and Mailath and Zemsky (1991) do not work if the cartel can only collect a transfer from a cartel member if that cartel member wins the auction (for example if transfers are arranged through subcontracting). Although Marshall and Marx (2008) provide some results for environments when transfers can only be required from winning cartel members, a full characterization of what is possible in this environment remains an open question. The results of McAfee and McMillan (1992) suggest that for first-price auctions, the assumption of an all-inclusive cartel is important for the existence of a profitable cartel mechanism that is ex-post budget balanced, and it remains an open question whether this is possible when the cartel is not all-inclusive. The issue of individual rationality for cartels at first-price auctions receives some attention in McAfee and McMillan (1992) and in Marshall and Marx (2007), but open questions remain there as well.

\footnotetext{
22 For examples of this type of mechanism, see U.S. v. Ronald Pook (1988), U.S. v. Seville Industrial Machinery (1988), and District of Columbia v. George Basiliko, et al. (1992).
} 


\section{Appendix A: Proof of Lemma 1}

First, consider a feasible solution $\left(p, m_{1}, m_{2}\right)$ of linear program (1)-(7). We construct a solution $\left(\rho, M_{1}, M_{2}, J_{1}, J_{2}\right)$ to the linear program (8)-(14) and then show that it is feasible with the same objective function value. Let $\rho\left(b_{1}, b_{2}, v_{1}, v_{2}\right)=$ $p\left(b_{1}, b_{2} \mid v_{1}, v_{2}\right)$, for $i \in\{1,2\}$, let $M_{i}\left(v_{i}\right)=\sum_{v_{-i} \in \mathcal{V}_{-i}} m_{i}\left(v_{1}, v_{2}\right) f_{-i}\left(v_{-i}\right)$, and let

$$
J_{1}\left(v_{1}, v_{1}^{\prime}, b_{1}\right)=\max _{b_{1}^{\prime} \in \mathcal{B}} \sum_{v_{2} \in \mathcal{V}_{2}, b_{2} \in \mathcal{B}} p\left(b_{1}, b_{2} \mid v_{1}^{\prime}, v_{2}\right) u_{1}\left(b_{1}^{\prime}, b_{2}, v_{1}\right) f_{2}\left(v_{2}\right)
$$

with an analogous definition for $J_{2}\left(v_{2}, v_{2}^{\prime}, b_{2}\right)$. It is straightforward to show that constraints (10), (11), (13) and (14) are satisfied. Furthermore, for $i \in\{1,2\}$, consider the deviation function $\delta_{i}^{*}\left(b_{i}\right)$ defined by

$$
J_{1}\left(v_{1}, v_{1}^{\prime}, b_{1}\right)=\sum_{v_{2} \in \mathcal{V}_{2}, b_{2} \in \mathcal{B}} p\left(b_{1}, b_{2} \mid v_{1}^{\prime}, v_{2}\right) u_{1}\left(\delta_{1}^{*}\left(b_{1}\right), b_{2}, v_{1}\right) f_{2}\left(v_{2}\right)
$$

with an analogous definition for $J_{2}\left(v_{2}, v_{2}^{\prime}, b_{2}\right)$. Constraint (4) implies that for $i \in$ $\{1,2\}$,

$$
U_{i}\left(p \mid v_{i}\right) \geq U_{i}^{*}\left(p, \delta_{i}^{*}, v_{i}^{\prime} \mid v_{i}\right)=\sum_{b_{i} \in \mathcal{B}} J_{i}\left(v_{i}, v_{i}^{\prime}, b_{i}\right)-M_{i}\left(v_{i}^{\prime}\right)
$$

Therefore, (12) is satisfied. It can be verified that the corresponding objective values are the same.

Second, consider a feasible solution $\left(\rho, M_{1}, M_{2}, J_{1}, J_{2}\right)$ to (8)-(14). Letting $p\left(b_{1}, b_{2} \mid v_{1}, v_{2}\right)=\rho\left(b_{1}, b_{2}, v_{1}, v_{2},\right)$ and for $i \in\{1,2\}, m_{i}\left(v_{1}, v_{2}\right)=M_{i}\left(v_{i}\right)$, then $\left(p, m_{1}, m_{2}\right)$ is a feasible solution to (1)-(7) and has the same objective function value. It is obvious that constraints (2) and (3) are satisfied. To see that the incentive compatibility constraints are also satisfied, note that for any $v_{1} \in \mathcal{V}_{1}, v_{1}^{\prime} \in \mathcal{V}_{1}, b_{1} \in \mathcal{B}$, and $\delta_{1}\left(b_{1}\right) \in \mathcal{B},(13)$ and (14) imply

$$
J_{1}\left(v_{1}, v_{1}^{\prime}, b_{1}\right) \geq \sum_{v_{2} \in \mathcal{V}_{2}, b_{2} \in \mathcal{B}} p\left(b_{1 i}, b_{2} \mid v_{1}^{\prime}, v_{2}\right) u_{1}\left(\delta_{1}\left(b_{1}\right), b_{2}, v_{1}\right) f_{2}\left(v_{2}\right)
$$

and analogously for bidder 2. Furthermore, (12) implies (4).

\section{Appendix B: Proof of Lemma 4}

Define $(\bar{\xi}, \bar{\mu}, \bar{\lambda}, \bar{\delta})$ as follows: 


$$
\bar{\xi}\left(h, h, j, j^{\prime}\right)
$$

$$
\equiv\left\{\begin{array}{ll}
2 f(h) / f(l), & \text { if } j^{\prime}>j \text { and } j^{\prime} \in\{1,3, \ldots, 2 B-1\} \\
j f(h) / f(l), & \text { if } j=j^{\prime} \in\{0,1,2, \ldots, 2 B\} \\
f(h) / f(l), & \text { if } j^{\prime}=j+1 \in\{2,4, \ldots, 2 B\} \\
2 B f(h) / f(l), & \text { if } j=j^{\prime}>2 B \\
0, & \text { otherwise }
\end{array} \quad, \quad \bar{\mu}(h, h)=2 B \frac{f(h)}{f(l)}\right.
$$

$\bar{\xi}\left(l, h, j, j^{\prime}\right)$

$$
\begin{aligned}
& \equiv\left\{\begin{array}{ll}
2 f(h) / f(l), & \text { if } j^{\prime}>j \text { and } j^{\prime} \in\{3, \ldots, 2 B-1\} \\
(j-1) f(h) / f(l), & \text { if } j=j^{\prime} \in\{2,4, \ldots, 2 B\} \\
j f(h) / f(l), & \text { if } j=j^{\prime} \in\{3,5, \ldots, 2 B-1\} \\
f(h) / f(l), & \text { if } j \in\{0,1\} \text { and } j^{\prime}=2 \\
(2 B-1) f(h) / f(l), & \text { if } j=j^{\prime}>2 B \\
0, & \text { otherwise }
\end{array}, \quad \bar{\mu}(h, l)=2 B-1\right. \\
& \bar{\xi}\left(h, l, j, j^{\prime}\right) \equiv\left\{\begin{array}{ll}
2 B-1, & \text { if } j^{\prime}=0 \\
0, & \text { otherwise }
\end{array}, \quad \bar{\mu}(l, h)=\frac{f(h)}{f(l)}(2 B-1)\right. \\
& \bar{\xi}\left(l, l, j, j^{\prime}\right) \equiv\left\{\begin{array}{ll}
2 B / f(l), & \text { if } j^{\prime}=0 \\
0, & \text { otherwise }
\end{array}, \quad \bar{\mu}(l, l)=\frac{2 B}{f(l)}\right. \\
& \bar{\lambda}(h, h)=\bar{\lambda}(h, l)=\bar{\lambda}(l, h) \equiv(h-l)\left(2 B f(l)+\frac{f(h)^{2}}{2 B f(l)}\right) \\
& \bar{\lambda}(l, l) \equiv 2(h-l)(B(f(h)-2)+1) f(h) / f(l) \\
& \bar{\delta} \equiv 0 .
\end{aligned}
$$

We show that $(\bar{\xi}, \bar{\mu}, \bar{\lambda}, \bar{\delta})$ is feasible to the dual linear program (21)-(25).

It is easy to verify that $(\bar{\xi}, \bar{\mu}, \bar{\lambda}, \bar{\delta})$ is feasible to constraints (22), (24), and (25). We focus on (23), or $\lambda(v, \bar{v}) \geq \phi(v, \bar{v}, j, \bar{j})$, where

$$
\begin{aligned}
\phi(v, \bar{v}, j, \bar{j}) \equiv & u\left(b_{j}, b_{\bar{j}}, v\right)+u\left(b_{\bar{j}}, b_{j}, \bar{v}\right) \\
& -\sum_{v^{\prime}} \sum_{j^{\prime} \in \mathcal{B}} \xi\left(v, v^{\prime}, j, j^{\prime}\right) u\left(b_{j^{\prime}}, b_{\bar{j}}, v^{\prime}\right) \\
& -\sum_{v^{\prime}} \sum_{j^{\prime} \in \mathcal{B}} \xi\left(\bar{v}, v^{\prime}, \bar{j}, j^{\prime}\right) u\left(b_{j^{\prime}}, b_{j}, v^{\prime}\right) \\
& +\sum_{v^{\prime}} \mu\left(v, v^{\prime}\right) u\left(b_{j}, b_{\bar{j}}, v\right)+\sum_{v^{\prime}} \mu\left(\bar{v}, v^{\prime}\right) u\left(b_{\bar{j}}, b_{j}, \bar{v}\right) .
\end{aligned}
$$

We do this by considering each one of the four possible combinations of $v$ and $\bar{v}$ : First consider $v=\bar{v}=h$. Without loss of generality, we only need to consider cases when $j \geq \bar{j}$. 
1. $2 B \geq j>\bar{j}+1$ and $j$ is an even number.

$$
\begin{aligned}
\phi(h, h, j, \bar{j})= & u\left(b_{j}, b_{\bar{j}}, h\right)(1+\mu(h, h)+\mu(h, l)-\xi(h, h, j, j)) \\
& -\xi(h, h, \bar{j}, j) u\left(b_{j}, b_{j}, h\right) \\
& -\sum_{j^{\prime}: j^{\prime}>j} \xi\left(h, h, j, j^{\prime}\right) u\left(b_{j^{\prime}}, b_{\bar{j}}, h\right) \\
& -\sum_{j^{\prime}: j^{\prime}>j} \xi\left(h, h, \bar{j}, j^{\prime}\right) u\left(b_{j^{\prime}}, b_{j}, h\right) \\
= & (h-l)\left(\left(1-\frac{f(h)}{2 B} j\right)\left(\frac{2 B}{f(l)}-\frac{f(h)}{f(l)} j\right)\right. \\
& \left.-4 \frac{f(h)}{f(l)} \sum_{k=j / 2}^{B-1}\left(1-\frac{2 k+1}{2 B} f(h)\right)\right) \\
= & 2(h-l) B f(l)<\lambda(h, h) .
\end{aligned}
$$

2. $j=\bar{j}+1 \leq 2 B$ and $j$ is an even number.

$$
\begin{aligned}
\phi(h, h, j, j-1)= & u\left(b_{j}, b_{j-1}, h\right)(1+\mu(h, h)+\mu(h, l)-\xi(h, h, j, j)) \\
& -\xi(h, h, j-1, j) u\left(b_{j}, b_{j}, h\right) \\
& -\sum_{j^{\prime}: j^{\prime}>j} \xi\left(h, h, j, j^{\prime}\right) u\left(b_{j^{\prime}}, b_{j-1}, h\right) \\
& -\sum_{j^{\prime}: j^{\prime}>j} \xi\left(h, h, j-1, j^{\prime}\right) u\left(b_{j^{\prime}}, b_{j}, h\right) \\
& -\xi(h, h, j, j-1) u\left(b_{j-1}, b_{j-1}, h\right) \\
= & (h-l)\left[2 B f(l)-\frac{1}{2}\left(1-\frac{f(l)}{2 B} j\right) \frac{f(h)}{f(l)}\right]<\lambda(h, h) .
\end{aligned}
$$

3. $j=\bar{j} \leq 2 B$ and $j$ is an even number.

$$
\begin{aligned}
\phi(h, h, j, j)= & 2 u\left(b_{j}, b_{j}, h\right)(1+\mu(h, h)+\mu(h, l)-\xi(h, h, j, j)) \\
& -2 \sum_{j^{\prime}: j^{\prime}>j} \xi\left(h, h, j, j^{\prime}\right) u\left(b_{j^{\prime}}, b_{j}, h\right) \\
= & (h-l)\left(\left(1-\frac{f(h)}{2 B} j\right)\left(\frac{2 B}{f(l)}-\frac{f(h)}{f(l)} j\right)\right. \\
& \left.-4 \frac{f(h)}{f(l)} \sum_{k=j / 2}^{B-1}\left(1-\frac{2 k+1}{2 B} f(h)\right)\right) \\
= & 2(h-l) B f(l)<\lambda(h, h) .
\end{aligned}
$$


4. $2 B>j>\bar{j}$ and $j$ is an odd number.

$$
\begin{aligned}
\phi(h, h, j, \bar{j})= & u\left(b_{j}, b_{\bar{j}}, h\right)(1+\mu(h, h)+\mu(h, l)-\xi(h, h, j, j)) \\
& -\xi(h, h, \bar{j}, j) u\left(b_{j}, b_{j}, h\right) \\
& -\sum_{j^{\prime}: j^{\prime}>j+1} \xi\left(h, h, j, j^{\prime}\right) u\left(b_{j^{\prime}}, b_{\bar{j}}, v^{\prime}\right) \\
& -\sum_{j^{\prime}: j^{\prime}>j+1} \xi\left(h, h, \bar{j}, j^{\prime}\right) u\left(b_{j^{\prime}}, b_{j}, h\right) \\
& -\xi(h, h, j, j+1) u\left(b_{j+1}, b_{\bar{j}}, v^{\prime}\right) \\
= & (h-l)\left[\left(1-\frac{f(h)}{2 B} j\right)\left(\frac{2 B}{f(l)}-(j+1) \frac{f(h)}{f(l)}\right)\right. \\
& -4 \frac{f(h)}{f(l)} \sum_{k=(j+1) / 2}^{B-1}\left(1-\frac{2 k+1}{2 B} f(h)\right) \\
& \left.-\left(1-\frac{(j+1) f(h)}{2 B}\right) \frac{f(h)}{f(l)}\right] \\
= & (h-l) 2 B f(l)<\lambda(h, h)
\end{aligned}
$$

5. $j=\bar{j}<2 B$ and $j$ is an odd number.

$$
\begin{aligned}
\phi(h, h, j, j)= & 2 u\left(b_{j}, b_{j}, h\right)(1+\mu(h, h)+\mu(h, l)-\xi(h, h, j, j)) \\
& -2 \sum_{\substack{j^{\prime}: j^{\prime}>j+1\\
}} \xi\left(h, h, j, j^{\prime}\right) u\left(b_{j^{\prime}}, b_{j}, h\right) \\
& -2 \xi(h, h, j, j+1) u\left(b_{j+1}, b_{j}, h\right) \\
= & (h-l)\left(2 B f(l)+\frac{f(h)^{2}}{2 B f(l)}\right)=\lambda(h, h) .
\end{aligned}
$$

6. $j>2 B$ and $j>\bar{j}$.

$$
\begin{aligned}
\phi(h, h, j, \bar{j}) & =u\left(b_{j}, b_{\bar{j}}, h\right)(1+\mu(h, h)+\mu(h, l)-\xi(h, h, j, j)) \\
& =u\left(b_{j}, b_{\bar{j}}, h\right)(1+\mu(h, l)) \\
& =(h-l)\left(2 B-j f_{h}\right)<2 B(h-l) f_{l}<\lambda(h, h)
\end{aligned}
$$

7. $j=\bar{j}>2 B$.

$$
\begin{aligned}
\phi(h, h, j, j) & =2 u\left(b_{j}, b_{j}, h\right)(1+\mu(h, h)+\mu(h, l)-\xi(h, h, j, j)) \\
& =(h-l)\left(2 B-j f_{h}\right)<2 B(h-l) f_{l}<\lambda(h, h) .
\end{aligned}
$$

Now consider $v=h$ and $\bar{v}=l$. 
1. $2 B \geq j>\bar{j}, j>0$ and $j$ is an even number.

$$
\begin{aligned}
\phi(h, l, j, \bar{j})= & u\left(b_{j}, b_{\bar{j}}, h\right)(1+\mu(h, h)+\mu(h, l)-\xi(h, h, j, j)) \\
& -\sum_{j^{\prime}: j^{\prime}>j} \xi\left(h, h, j, j^{\prime}\right) u\left(b_{j^{\prime}}, b_{\bar{j}}, h\right)-\sum_{j^{\prime}: j^{\prime}>j} \xi\left(l, h, \bar{j}, j^{\prime}\right) u\left(b_{j^{\prime}}, b_{j}, h\right) \\
= & (h-l)\left(\left(1-\frac{f(h)}{2 B} j\right)\left(\frac{2 B}{f(l)}-\frac{f(h)}{f(l)} j\right)\right. \\
& \left.-4 \frac{f(h)}{f(l)} \sum_{k=j / 2}^{B-1}\left(1-\frac{2 k+1}{2 B} f(h)\right)\right) \\
= & 2(h-l) B f(l)<\lambda(h, l) .
\end{aligned}
$$

2. $2 B>j>\bar{j}, j \geq 3$ and $j$ is an odd number.

$$
\begin{aligned}
\phi(h, l, j, \bar{j})= & u\left(b_{j}, b_{\bar{j}}, h\right)(1+\mu(h, h)+\mu(h, l)-\xi(h, h, j, j)) \\
& -\sum_{j^{\prime}: j^{\prime}>j+1} \xi\left(h, h, j, j^{\prime}\right) u\left(b_{j^{\prime}}, b_{\bar{j}}, h\right) \\
& -\sum_{j^{\prime}: j^{\prime}>j+1} \xi\left(l, h, \bar{j}, j^{\prime}\right) u\left(b_{j^{\prime}}, b_{j}, h\right) \\
& -\xi(l, h, \bar{j}, j) u\left(b_{j}, b_{j}, h\right)-\xi(h, h, j, j+1) u\left(b_{j+1}, b_{\bar{j}}, h\right) \\
= & (h-l)\left[\left(1-\frac{f(h)}{2 B} j\right)\left(\frac{2 B}{f(l)}-\frac{f(h)}{f(l)}(j+1)\right)\right. \\
& -4 \frac{f(h)}{f(l)} \sum_{k=(j+1) / 2}^{B-1}\left(1-\frac{2 k+1}{2 B} f(h)\right) \\
& \left.-\left(1-\frac{f(h)}{2 B}(j+1)\right) \frac{f(h)}{f(l)}\right] \\
= & 2(h-l) B f(l)<\lambda(h, l)
\end{aligned}
$$

3. $j=1$ and $\bar{j}=0$.

$$
\phi(h, l, 1,0)=(h-l)\left(2 B f(l)+\frac{f(h)^{2}}{2 B f(l)}\right)=\lambda(h, l) .
$$


4. $2 B \geq j=\bar{j} \geq 2$ and $j$ is an even number.

$$
\begin{aligned}
\phi(h, l, j, j)= & u\left(b_{j}, b_{j}, h\right)(2+\mu(h, h)+\mu(h, l)-\xi(h, h, j, j)-\xi(l, h, j, j)) \\
& -\sum_{j^{\prime}: j^{\prime}>j} \xi\left(h, h, j, j^{\prime}\right) u\left(b_{j^{\prime}}, b_{j}, h\right)-\sum_{j^{\prime}: j^{\prime}>j} \xi\left(l, h, j, j^{\prime}\right) u\left(b_{j^{\prime}}, b_{j}, h\right) \\
& +u\left(b_{j}, b_{j}, l\right)(\mu(l, l)+\mu(l, h)) \\
= & (h-l)\left[\left(1-\frac{f(h)}{2 B} j\right)\left(\frac{B}{f(l)}+\frac{1}{2}-\frac{f(h)}{f(l)}\left(j-\frac{1}{2}\right)\right)\right. \\
& -4 \frac{f(h)}{f(l)} \sum_{k=j / 2}^{B-1}\left(1-\frac{2 k+1}{2 B} f(h)\right) \\
& \left.-\left(\frac{2 B}{f(l)}+\frac{f(h)}{f(l)}(2 B-1)\right) \frac{j}{4 B} f(h)\right] \\
= & (h-l)\left(2 B f(l)-\frac{1}{2 f(l)}\left(2 B-1+j f(h)^{2}\right)-\frac{1}{4 B} j f(h)\right)<\lambda(h, l) .
\end{aligned}
$$

5. $2 B>j=\bar{j} \geq 3$ and $j$ is an odd number.

$$
\begin{aligned}
\phi(h, l, j, j)= & u\left(b_{j}, b_{j}, h\right)(2+\mu(h, h)+\mu(h, l)-\xi(h, h, j, j)-\xi(l, h, j, j)) \\
& -\sum_{j^{\prime}: j^{\prime}>j} \xi\left(h, h, j, j^{\prime}\right) u\left(b_{j^{\prime}}, b_{j}, h\right)-\sum_{j^{\prime}: j^{\prime}>j} \xi\left(l, h, j, j^{\prime}\right) u\left(b_{j^{\prime}}, b_{j}, h\right) \\
& +u\left(b_{j}, b_{j}, l\right)(\mu(l, l)+\mu(l, h))-\xi(h, h, j, j+1) u\left(b_{j+1}, b_{j}, h\right) \\
= & (h-l)\left[\left(1-\frac{f(h)}{2 B} j\right)\left(\frac{B}{f(l)}+\frac{1}{2}-\frac{f(h)}{f(l)} j\right)\right. \\
& -\left(1-\frac{f(h)}{2 B}(j+1)\right) \frac{f(h)}{f(l)} \\
& -4 \frac{f(h)}{f(l)} \sum_{k=(j+1) / 2}^{B-1}\left(1-\frac{2 k+1}{2 B} f(h)\right) \\
& \left.-\left(\frac{2 B}{f(l)}+\frac{f(h)}{f(l)}(2 B-1)\right) \frac{j}{4 B} f(h)\right] \\
= & (h-l)\left(2 B f(l)-\frac{f(h)}{4 B f(l)} j-\frac{2 B+j f^{2}-f-1}{2 f(l)}\right)<\lambda(h, l) .
\end{aligned}
$$

6. $j=\bar{j}=0$.

$$
\begin{aligned}
\phi(h, l, 0,0)= & u\left(b_{0}, b_{0}, h\right)(2+\mu(h, h)+\mu(h, l))-\xi(l, h, 0,2) u\left(b_{2}, b_{0}, h\right) \\
& -\sum_{j^{\prime}: j^{\prime}>1} \xi\left(h, h, 0, j^{\prime}\right) u\left(b_{j^{\prime}}, b_{0}, h\right)-\sum_{j^{\prime}: j^{\prime}>3} \xi\left(l, h, 0, j^{\prime}\right) u\left(b_{j^{\prime}}, b_{0}, h\right)
\end{aligned}
$$




$$
\begin{aligned}
= & (h-l)\left[\left(\frac{B}{f(l)}+\frac{1}{2}\right)-4 \frac{f(h)}{f(l)} \sum_{k=1}^{B-1}\left(1-\frac{2 k+1}{2 B} f(h)\right)\right. \\
& \left.-2 \frac{f(h)}{f(l)}\left(1-\frac{1}{2 B} f(h)\right)-\frac{f(h)}{f(l)}\left(1-\frac{2}{2 B} f(h)\right)\right] \\
= & (h-l)\left(2 B f(l)-\frac{2 B-f(h)-1}{2 f(l)}\right)<\lambda(h, l) .
\end{aligned}
$$

7. $j=\bar{j}=1$.

$$
\begin{aligned}
\phi(h, l, 1,1)= & u\left(b_{1}, b_{1}, h\right)(2+\mu(h, h)+\mu(h, l))-\xi(l, h, 1,2) u\left(b_{2}, b_{0}, h\right) \\
& -\sum_{j^{\prime}: j^{\prime}>1} \xi\left(h, h, 1, j^{\prime}\right) u\left(b_{j^{\prime}}, b_{1}, h\right)-\sum_{j^{\prime}: j^{\prime}>3} \xi\left(l, h, 1, j^{\prime}\right) u\left(b_{j^{\prime}}, b_{1}, h\right) \\
= & (h-l)\left[\left(1-\frac{1}{2 B} f(h)\right)\left(\frac{B}{f(l)}+\frac{1}{2}\right)\right. \\
& -4 \frac{f(h)}{f(l)} \sum_{k=1}^{B-1}\left(1-\frac{2 k+1}{2 B} f(h)\right) \\
& \left.-2 \frac{f(h)}{f(l)}\left(1-\frac{1}{2 B} f(h)\right)-\frac{f(h)}{f(l)}\left(1-\frac{2}{2 B} f(h)\right)\right] \\
= & (h-l)\left(2 B f(l)-\frac{4 B^{2}-2 B+f(h) f(l)}{4 B f(l)}\right)<\lambda(h, l) .
\end{aligned}
$$

8. $j>2 B$ and $j>\bar{j}$.

$$
\begin{aligned}
\phi(h, l, j, \bar{j}) & =u\left(b_{j}, b_{\bar{j}}, h\right)(1+\mu(h, h)+\mu(h, l)-\xi(h, h, j, j)) \\
& =(h-l)\left(1-\frac{f(h)}{2 B} j\right)\left(\frac{2 B}{f(l)}-\frac{f(h)}{f(l)} 2 B\right) \\
& =(h-l) 2 B\left(f(l)-\frac{j-2 B}{2 B} f(h)\right)<\lambda(h, l) .
\end{aligned}
$$

9. $j=\bar{j}>2 B$.

$$
\begin{aligned}
\phi(h, l, j, j)= & u\left(b_{j}, b_{j}, h\right)(2+\mu(h, h)+\mu(h, l)-\xi(h, h, j, j)-\xi(l, h, j, j)) \\
& +u\left(b_{j}, b_{j}, l\right)(\mu(l, l)+\mu(l, h)) \\
= & (h-l)\left[\left(1-\frac{f(h)}{2 B} j\right)\left(\frac{B}{f(l)}+\frac{1}{2}-\frac{f(h)}{f(l)}\left(2 B-\frac{1}{2}\right)\right)\right. \\
& \left.-\left(\frac{2 B}{f(l)}+\frac{f(h)}{f(l)}(2 B-1)\right) \frac{j}{4 B} f(h)\right] \\
= & \frac{1}{4 B(1-f)}\left(-8 B^{2} f+4 B^{2}+2 B+j f(2 B f-4 B+f-1)\right)
\end{aligned}
$$




$$
\begin{aligned}
& <\frac{1}{4 B(1-f)}\left(-8 B^{2} f+4 B^{2}+2 B+2 B f(2 B f-4 B+f-1)\right) \\
& =(h-l)\left[2 B f(l)-\frac{(2 B-1)\left(1+f(h)^{2}\right)+f(h)}{2 f(l)}\right] \\
& <(h-l) 2 B f(l)<\lambda(h, l) .
\end{aligned}
$$

10. $j<\bar{j}$.

$$
\begin{aligned}
& \phi(h, l, j, \bar{j})=u\left(b_{\bar{j}}, b_{j}, l\right)(1+\mu(l, h)+\mu(l, l))-\xi(h, h, j, \bar{j}) u\left(b_{\bar{j}}, b_{\bar{j}}, h\right) \\
& -\sum_{j^{\prime}: j^{\prime}>\bar{j}} \xi\left(h, h, j, j^{\prime}\right) u\left(b_{j^{\prime}}, b_{\bar{j}}, h\right)-\sum_{j^{\prime}: j^{\prime}>\bar{j}} \xi\left(l, h, \bar{j}, j^{\prime}\right) u\left(b_{j^{\prime}}, b_{j}, h\right) \\
& <0<\lambda(h, l) .
\end{aligned}
$$

Finally, consider $v=\bar{v}=l$. Without loss of generality, we only consider $j \geq \bar{j}$.

1. $2 B>j>\bar{j}, j>2$ and $j$ is an even number.

$$
\begin{aligned}
\phi(l, l, j, \bar{j})= & u\left(b_{j}, b_{\bar{j}}, l\right)(1+\mu(l, l)+\mu(l, h))-\sum_{j^{\prime}: j^{\prime}>j} \xi\left(l, h, j, j^{\prime}\right) u\left(b_{j^{\prime}}, b_{\bar{j}}, h\right) \\
& -\sum_{j^{\prime}: j^{\prime}>j} \xi\left(l, h, \bar{j}, j^{\prime}\right) u\left(b_{j^{\prime}}, b_{j}, h\right)-\xi(l, h, j, j) u\left(b_{j}, b_{\bar{j}}, h\right) \\
= & (h-l)\left(-\frac{f(h)}{2 B} j\left(1+\frac{f(h)}{f(l)}(2 B-1)+\frac{2 B}{f(l)}\right)\right. \\
& \left.-4 \frac{f(h)}{f(l)} \sum_{k=j / 2}^{B-1}\left(1-\frac{2 k+1}{2 B} f(h)\right)\right) \\
& -(h-l)\left(1-\frac{f(h)}{2 B} j\right)(j-1) \frac{f(h)}{f(l)} \\
= & (h-l)\left[\frac{f(h)}{f(l)}\left(2 B(f(h)-2)+2-\left(1+f(h) j+\frac{j}{2 B} f(l)\right)\right)\right] \\
< & \lambda(l, l) .
\end{aligned}
$$

2. $j=2>\bar{j}$

$$
\begin{aligned}
\phi(l, l, 2, \bar{j})= & u\left(b_{2}, b_{\bar{j}}, l\right)(1+\mu(l, l)+\mu(l, h))-\sum_{j^{\prime}: j^{\prime}>2} \xi\left(l, h, 2, j^{\prime}\right) u\left(b_{j^{\prime}}, b_{\bar{j}}, h\right) \\
& -\sum_{j^{\prime}: j^{\prime}>2} \xi\left(l, h, \bar{j}, j^{\prime}\right) u\left(b_{j^{\prime}}, b_{2}, h\right)-\xi(l, h, 2,2) u\left(b_{2}, b_{\bar{j}}, h\right) \\
& -\xi(l, h, \bar{j}, 2) u\left(b_{2}, b_{2}, h\right) \\
< & \phi(l, l, j, \bar{j}) \text { for } j \text { in case } 1 . \\
< & \lambda(l, l) .
\end{aligned}
$$


3. $2 B>j>\bar{j}$ and $j \geq 3$ is an odd number.

$$
\begin{aligned}
\phi(l, l, j, \bar{j})= & u\left(b_{j}, b_{\bar{j}}, l\right)(1+\mu(l, l)+\mu(l, h)) \\
& -\sum_{j^{\prime}: j^{\prime}>j} \xi\left(l, h, j, j^{\prime}\right) u\left(b_{j^{\prime}}, b_{\bar{j}}, h\right) \\
& -\sum_{j^{\prime}: j^{\prime}>j} \xi\left(l, h, \bar{j}, j^{\prime}\right) u\left(b_{j^{\prime}}, b_{j}, h\right)-\xi(l, h, j, j) u\left(b_{j}, b_{\bar{j}}, h\right) \\
& -\xi(l, h, \bar{j}, j) u\left(b_{j}, b_{j}, h\right) \\
= & -(h-l) \frac{f(h)}{2 B} j\left(1+\frac{f(h)}{f(l)}(2 B-1)+\frac{2 B}{f(l)}\right) \\
& -(h-l) \frac{f(h)}{f(l)}\left(4 \sum_{k=(j+1) / 2}^{B-1}\left(1-\frac{2 k+1}{2 B} f(h)\right)\right. \\
& \left.+\left(1-\frac{f(h)}{2 B} j\right)(j+1)\right) \\
= & (h-l)\left(\frac{f(h)}{f(l)}(2 B(f(h)-2)+2\right. \\
& \left.-\left(1+f(h) j+\frac{f(l) j+f(h)}{2 B}\right)\right)<\lambda(l, l) .
\end{aligned}
$$

4. $2 B \geq j=\bar{j} \geq 2$, and $j$ is an even number.

$$
\begin{aligned}
\phi(l, l, j, j)= & 2 u\left(b_{j}, b_{j}, l\right)(1+\mu(l, l)+\mu(l, h))-2 \sum_{j^{\prime}: j^{\prime}>j} \xi\left(l, h, j, j^{\prime}\right) u\left(b_{j^{\prime}}, b_{j}, h\right) \\
& -2 \xi(l, h, j, j) u\left(b_{j}, b_{j}, h\right) \\
= & (h-l)\left[\frac{f(h)}{f(l)}\left(2 B(f(h)-2)+2-\left(1+f(h) j+\frac{j}{2 B} f(l)\right)\right)\right] \\
< & \lambda(l, l) .
\end{aligned}
$$

5. $2 B>j=\bar{j} \geq 3$ and $j$ is an odd number.

$$
\begin{aligned}
\phi(l, l, j, j)= & 2 u\left(b_{j}, b_{j}, l\right)(1+\mu(l, l)+\mu(l, h)) \\
& -2 \sum_{\substack{j^{\prime}: j^{\prime} \geq j+2\\
}} \xi\left(l, h, j, j^{\prime}\right) u\left(b_{j^{\prime}}, b_{j}, h\right) \\
& -2 \xi(l, h, j, j) u\left(b_{j}, b_{j}, h\right) \\
= & -(h-l) \frac{f(h)}{2 B} j\left(1+\frac{f(h)}{f(l)}(2 B-1)+\frac{2 B}{f(l)}\right) \\
& -(h-l) \frac{f(h)}{f(l)}\left(4 \sum_{k=(j+1) / 2}^{B-1}\left(1-\frac{2 k+1}{2 B} f(h)\right)\right.
\end{aligned}
$$




$$
\begin{aligned}
& \left.+\left(1-\frac{f(h)}{2 B} j\right)(j+1)\right) \\
= & (h-l)\left(\frac{f(h)}{f(l)}(2 B(f(h)-2)+2\right. \\
& \left.\left.-\left(1+f(h) j+\frac{f(l) j+f(h)}{2 B}\right)\right)\right)<\lambda(l, l) .
\end{aligned}
$$

6. $j=\bar{j}=1$.

$$
\begin{aligned}
\phi(l, l, j, j)= & 2 u\left(b_{j}, b_{j}, l\right)(1+\mu(l, l)+\mu(l, h)) \\
& -2 \sum_{\substack{j^{\prime}: j^{\prime} \geq j+2\\
}} \xi\left(l, h, j, j^{\prime}\right) u\left(b_{j^{\prime}}, b_{j}, h\right) \\
& -2 \xi(l, h, j, j) u\left(b_{j}, b_{j}, h\right)-2 \xi(l, h, j, 2) u\left(b_{2}, b_{j}, h\right) \\
< & \phi(l, l, j, \bar{j}) \text { for } j \text { in case } 5 . \\
< & \lambda(l, l) .
\end{aligned}
$$

7. $j=\bar{j}=0$.

$$
\begin{aligned}
\phi(l, l, 0,0) & =-2 \sum_{j^{\prime}: j^{\prime} \geq 3} \xi\left(l, h, 0, j^{\prime}\right) u\left(b_{j^{\prime}}, b_{0}, h\right)-2 \xi(l, h, 0,2) u\left(b_{2}, b_{0}, h\right) \\
& =-(h-l) \frac{f(h)}{f(l)}\left(4 \sum_{k=1}^{B-1}\left(1-\frac{2 k+1}{2 B} f(h)\right)+2\left(1-\frac{f(h)}{2 B} 2\right)\right) \\
& =(h-l)\left[\frac{f(h)}{f(l)}(2 B(f(h)-2)+2)\right]=\lambda(l, l) .
\end{aligned}
$$

8. $j>2 B$ and $j>\bar{j}$.

$$
\begin{aligned}
\phi(l, l, j, \bar{j})= & u\left(b_{j}, b_{\bar{j}}, l\right)(1+\mu(l, l)+\mu(l, h))-\xi(l, h, j, j) u\left(b_{j}, b_{\bar{j}}, h\right) \\
= & (h-l)\left(-\frac{f(h)}{2 B} j\left(1+\frac{f(h)}{f(l)}(2 B-1)+\frac{2 B}{f(l)}\right)\right) \\
& -(h-l)\left(1-\frac{f(h)}{2 B} j\right)(2 B-1) \frac{f(h)}{f(l)} \\
= & (h-l)\left[\frac{f(h)}{f(l)}(2 B(f(h)-2)+2\right. \\
& \left.\left.-\left(1+j-2 B f(l)+\frac{j f(l)}{2 B}\right)\right)\right]<\lambda(l, l) .
\end{aligned}
$$


9. $j=\bar{j}>2 B$.

$$
\begin{aligned}
\phi(l, l, j, \bar{j})= & 2 u\left(b_{j}, b_{j}, l\right)(1+\mu(l, l)+\mu(l, h))-2 \xi(l, h, j, j) u\left(b_{j}, b_{j}, h\right) \\
= & (h-l)\left[\frac{f(h)}{f(l)}(2 B(f(h)-2)+2\right. \\
& \left.\left.-\left(1+j-2 B f(l)+\frac{j f(l)}{2 B}\right)\right)\right]<\lambda(l, l) .
\end{aligned}
$$

This completes the demonstration that $\lambda(v, \bar{v}) \geq \phi(v, \bar{v}, j, \bar{j})$ and proves that $(\bar{\xi}, \bar{\mu}, \bar{\lambda}, \bar{\delta})$ is feasible in the linear program $(21)-(25)$. Substituting $(\bar{\xi}, \bar{\mu}, \bar{\lambda}, \bar{\delta})$ into the dual objective function gives $D(B)=(h-l) f(h) f(l)\left(2+\frac{f(h)^{2}(1+f(l))}{2 B f(l)^{2}}\right)$.

\section{Appendix C: Additional proofs}

Proof of Proposition 1 It is clear that a bidder with value $l$ can do not better than to bid $l$. If bidder $i$ has value $h$, its expected payoff from bid $b_{i} \in\left[l, b^{*}\right]$ is

$$
\pi_{i}=(1-f(l)) \int_{l}^{b_{i}}\left(h-b_{i}\right) d F\left(b_{-i}\right)+f(l)\left(h-b_{i}\right)=f(l)(h-l),
$$

which is constant for all $b_{i} \in\left[l, b^{*}\right]$. A bid below $l$ has expected payoff of zero, and a bid $b_{i}>b^{*}$ has expected payoff of $h-b_{i}<h-b^{*}=f(l)(h-l)$. So the bidding strategy given in the proposition is a best reply.

Proof of Lemma 3 Let $b_{\text {low }}$ be the lowest bid recommended with positive probability in the optimal BCM. Thus, a bid of $b_{\text {low }}$ can only win the object through a tie. Assume a bidder with type $l$ has probability $p_{\text {low }}$ to be tied at a bid of $b_{\text {low }}$, and therefore receive surplus $\left(l-b_{\text {low }}\right) p_{\text {low }} / 2$. Suppose $b_{\text {low }}=l-t \Delta<l-2 \Delta$ for some $t>2$. Whenever the bidder receives the recommended bid $b_{\text {low }}=l-t \Delta$ from the center, by bidding $l-(t-1) \Delta$ instead, the bidder wins with probability at least $p_{l o w}$, which generates surplus $(t-1) \Delta p_{\text {low }}$, which is higher than $t \Delta p_{\text {low }} / 2=\left(l-b_{\text {low }}\right) p_{\text {low }} / 2$, which is the surplus from following the recommended bid $b_{\text {low }}$. Similar logic indicates that a type $h$ bidder also has no incentive to bid below $l-2 \Delta$.

Proof of Lemma 5 Let the type $l$ bidder bid $l$ and the type $h$ bidder mix on bids above $l$. Type $l$ bidder has surplus 0 and no incentive to deviate from $l$. Given the type $l$ bidder's strategy, one can show that a symmetric mixed strategy equilibrium exists. Now focus on the bid $b_{1}=l+\Delta$. The high type's surplus from bidding $b_{1}$ must be no less than $f(l)\left(h-b_{1}\right)$ because if he bids $b_{1}$, his surplus is at least $f(l)\left(h-b_{1}\right)$. If bid $b_{1}$ is not in an equilibrium bid, the surplus can only be higher than $f(l)\left(h-b_{1}\right)$. Therefore, for each bidder, $f(h) f(l)\left(h-b_{1}\right)$ is a lower bound for the expected surplus. 
Proof of Proposition 3 The noncooperative equilibrium of the first-price auction game is as follows: bidder 1 with value $l_{1}$ mixes just below $l_{1}$ using mixing distribution $G_{1}$ satisfying $\lim _{b \rightarrow l_{1}} G_{1}(b)=1$ and $G_{1}(b)<\frac{l_{2}-l_{1}}{l_{2}-b}$ for $b<l_{1}$; bidder 2 with value $l_{2}$ bids $l_{1}$; bidder 1 with value $h_{1}$ mixes on $\left(l_{1}, b^{m}\right]$ according to distribution

$$
F_{1}(b)= \begin{cases}0, & \text { if } b \leq l_{1} \\ \frac{1}{1-p_{1}}\left(\frac{h_{2}-b^{m}}{h_{2}-b}-p_{1}\right) & \text { if } b \in\left(l_{1}, b^{m}\right] \\ 1, & \text { if } b>b^{m}\end{cases}
$$

and 2 with value $h_{2}$ mixes on $\left[l_{1}, b^{m}\right]$ according to distribution

$$
F_{2}(b)= \begin{cases}0, & \text { if } b<l_{1} \\ \frac{1}{1-p_{2}}\left(\frac{h_{1}-b^{m}}{h_{1}-l_{1}}-p_{2}\right), & \text { if } b=l_{1} \\ \frac{1}{1-p_{2}}\left(\frac{h_{1}-b^{m}}{h_{1}-b}-p_{2}\right), & \text { if } b \in\left(l_{1}, b^{m}\right] \\ 1, & \text { if } b>b^{m} .\end{cases}
$$

To see that this is the equilibrium, note that if bidder 1 has value $h_{1}$, its expected payoff from bid $b \in\left(l_{1}, \bar{b}\right]$ is

$$
u_{1}\left(h_{1}, b\right)=\left(h_{1}-b\right)\left(p_{2}+\left(1-p_{2}\right) F_{2}(b)\right)=h_{1}-\bar{b},
$$

which is a constant with respect to $b$. Similarly, if bidder 2 has value $h_{2}$, its expected payoff from bid $b \in\left[l_{1}, \bar{b}\right]$ is

$$
u_{2}\left(h_{2}, b\right)=\left(h_{2}-b\right)\left(p_{1}+\left(1-p_{1}\right) F_{1}(b)\right)=h_{2}-\bar{b},
$$

which is also a constant with respect to $b$. Now we consider bidder 2 with type $l_{2}$. It has no incentive to bid below $l_{1}$. For $b \in\left[0, l_{1}\right)$,

$$
u_{2}\left(l_{2}, l_{1}\right)=\left(l_{2}-b\right) p_{1} G_{1}(b)<\left(l_{2}-l_{1}\right) p_{1}=u_{2}\left(l_{2}, l_{1}\right) .
$$

If it bids $b \in\left(l_{1}, l_{2}\right]$, the expected surplus is

$$
\begin{aligned}
u_{2}\left(l_{2}, b\right) & =\left(l_{2}-b\right)\left(p_{1}+\left(1-p_{1}\right) F_{1}(b)\right)=\left(l_{2}-b\right) p_{1} \frac{h_{2}-l_{1}}{h_{2}-b} \\
& <\left(l_{2}-l_{1}\right) p_{1}=u_{2}\left(l_{2}, l_{1}\right)
\end{aligned}
$$

where the inequality uses $b>l_{1}$. Thus, bidder 2 with type $l_{2}$ has no incentive to bid below or above $l_{1}$. Given the equilibrium the calculation of the expected total surplus is straightforward. 


\section{References}

Albert MR (2002) E-Buyer beware: why online auction fraud should be regulated. Am Bus Law J 39:575643

Aoyagi M (2003) Bid rotation and collusion in repeated auctions. J Econ Theor 112:79-105

Blume A, Heidhues P (2006) Private monitoring in auctions. J Econ Theor 131:179-211

District of Columbia, ex rel. John Payton, Corporation Counsel v. George Basiliko, et al. (1992) No. 91-2518, 1992 U.S. Dist. LEXIS 1260 (D.C. February 10, 1992)

Eatwell J, Milgate M, Newman P (1989) Allocation, information and markets. W. W. Norton \& Co, New York

Forge F (2006) Correlated equilibrium in games with incomplete information revisited. CORE Discussion Paper 2006/41, CEREMADE

Gayle W-R, Richard J-F (2008) Numerical solutions of asymmetric, first-price, independent private values auctions. Comput Econ 32:245-278

Graham DA, Marshall RC (1987) Collusive bidder behavior at single-object second price and english auctions. J Pol Econ 95:1217-1239

Hurwicz L (1973) The design of mechanisms for resource allocation. Am Econ Rev Papers Proc 63:1-30

Jamison JS, Hörner J (2008) Collusion with (Almost) no information, forthcoming in RAND J Econ

Kovacic WE, Marshall RC, Marx LM, Raiff ME (2006) Bidding rings and the design of anti-collusion measures for auctions and procurements. In: Dimitri N, Piga G, Spagnolo G (eds) Handbook of procurement, chapter 15. Cambridge University Press, Cambridge, pp 381-411

Laffont J-J, Martimort D (2002) The theory of inventives: the principal-agent model. Princeton University Press, Princeton

Ledyard JO (1989) Incentive compatibility. In: Eatwell J, Milgate M, Newman P (eds) Allocation, information and markets. W. W. Norton \& Co, New York

Lopomo G, Marshall RC, Marx LM (2005) Inefficiency of collusion at english auctions. Contrib Theor Econ 5(1), Article 4

Mailath G, Zemsky P (1991) Collusion in second price auctions with heterogeneous bidders. Games Econ Behav 3:467-486

Marshall RC, Marx LM (2007) Bidder collusion. J Econ Theor 133:374-402

Marshall RC, Marx LM (2008) The vulnerability of auctions to bidder collusion, forthingcoming in J Econ Theor

Marshall RC, Meurer MJ (2004) Bidder collusion and antitrust law: refining the analysis of price fixing to account for the special features of auction markets. Antitrust Law J 72:83-118

Marshall RC, Meurer MJ, Richard J-F, Stromquist W (1994) Numerical analysis of asymmetric first price auctions. Games Econ Behav 7:193-220

Mas-Colell A, Whinston MD, Green JR (1995) Microeconomic theory. Oxford University Press, New York

McAfee RP, McMillan J (1992) Bidding rings. Am Econ Rev 82:579-599

McMillan JMc (1994) Selling spectrum rights. J Econ Perspect 8(3):145-162

Milgrom P (1985) Auction theory. In: Bewley T (ed) Advances in economic theory, fifth world congress. Cambridge University Press, Cambridge, pp 1-32

Milgrom P (1989) Auctions and bidding: a primer. J Econ Perspect 3(3):3-22

Myerson RB (1982) Optimal coordination mechanisms in generalized principal-agent problems. J Math Econ 10:67-81

Myerson RB (1983) Mechanism design by an informed principal. Econometrica 51:1767-1797

Myerson RB (1985) Bayesian equilibrium and incentive compatibility. In: Hurwicz L, Schmeidler D, Sonnenschein H (eds) Social goals and social organization. Cambridge University Press, Cambridge pp 229-259

Myerson RB (1989) Mechanism design. In: Eatwell J, Milgate M, Newman P (eds) Allocation, information and markets. W.W. Norton \& Co, New York

Myerson RB (1991) Game theory. Harvard University Press, Cambridge

Nau R, Canovas SG, Hansen P (2003) On the geometry of Nash equilibria and correlated equilibria. Int J Game Theor 32:443-453

Oren SS, Rothkopf MH (1975) Optimal bidding in sequential auctions. Oper Res 23(6):1080-1090

Pesendorfer M (2000) A study of collusion in first-price auctions. Rev Econ Stud 67:381-411

Robinson MS (1985) Collusion and the choice of auction. RAND J Econ 16:141-145

Skrzypacz A, Hopenhayn H (2004) Tacit collusion in repeated auctions. J Econ Theor 114:153-169 
U.S. v. A-A-A Elec. Co., Inc. (1986) 788 F.2d 242 (4th Cir. 1986)

U.S. v. Addyston Pipe \& Steel Co. et al., 1897 LEXIS 2499 (E.D. Tenn. Feb. 5, 1897)

U.S. v. Raymond J. Lyons (1982) No. 81-1287, 1982 U.S. App. LEXIS 22194 (Feb. 1, 1982)

U.S. v. Ronald Pook (1988) No. 87-274, 1988 U.S. Dist. LEXIS 3398 (E.D. Pa. April 18, 1988)

U.S. v. Seville Industrial Machinery Corp. (1988) 696 F.Supp. 986 (D.N.J. 1988)

U.S. v. W.F. Brinkley \& Son Construction Company, Inc. (1986) 783 F.2d 1157 (4th Cir. 1986)

Wilson R (1987) Auction theory. In: Eatwell J, Milgate M, Newman P (eds) The New Palgrave. MacMillan, London 